INEL-95/0646

Distribution Category: UC-425

\title{
Fusion Safety Program Annual Report Fiscal Year 1995
}

\author{
Glen R. Longhurst \\ Lee C. Cadwallader \\ W. Jon Carmack \\ Thomas J. Dolan \\ Michael J. Gaeta \\ Don L. Hagrman \\ J. Stephen Herring \\ Kathryn A. McCarthy \\ Brad J. Merrill \\ Chester G. Motloch \\ David A. Petti \\ Published December 1995 \\ Idaho National Engineering Laboratory \\ Nuclear Engineering Department \\ Lockheed Idaho Technologies Company \\ Idaho Falls, Idaho 83415 \\ Prepared for the \\ U.S. Department of Energy \\ Office of Energy Research \\ Under DOE Idaho Operations Office \\ Contract DE-AC07-94ID13223
}

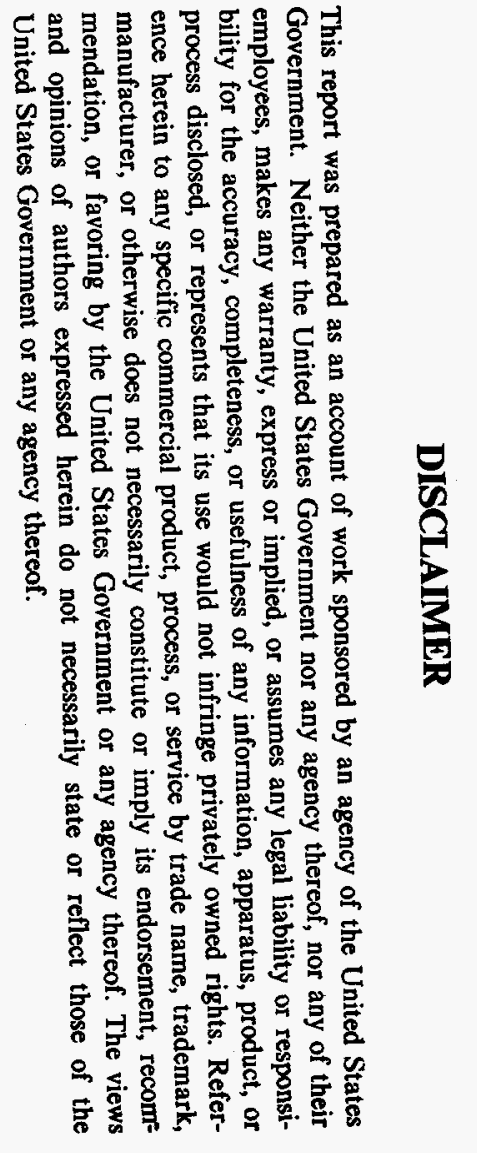




\section{DISCLAMMER}

Portions of this document may be illegible in electronic image products. Images are produced from the best available original document. 


\begin{abstract}
This report summarizes the major activities of the Fusion Safety Program in FY-95. The Idaho National Engineering Laboratory (INEL) is the designated lead laboratory, and Lockheed Idaho Technologies Company is the prime contractor for this program. The Fusion Safety Program was initiated in 1979. Activities are conducted at the INEL, at other DOE laboratories, and at other institutions. Among the technical areas covered in this report are tritium safety, beryllium safety, chemical reactions and activation product release, safety aspects of fusion magnet systems, plasma disruptions, risk assessment failure rate database development, and safety code development and application to fusion safety issues. Most of this work has been done in support of the International Thermonuclear Experimental Reactor (ITER). Also included in the report are summaries of the safety and environmental studies performed by the Fusion Safety Program for the Tokamak Physics Experiment and the Tokamak Fusion Test Reactor and the technical support for commercial fusion facility conceptual design studies. A final activity described is work to develop DOE Technical Standards for Safety of Fusion Test Facilities.
\end{abstract}




\section{CONTENTS}

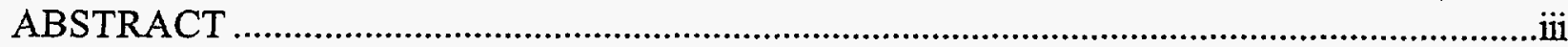

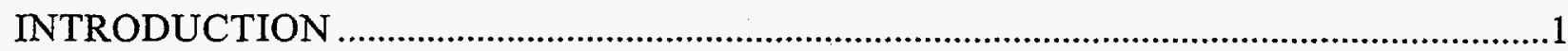

INTERNATIONAL THERMONUCLEAR EXPERIMENTAL REACTOR DESIGN AND

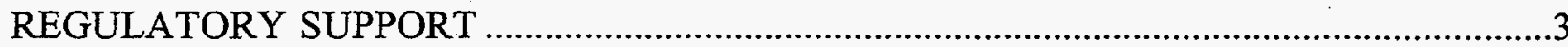

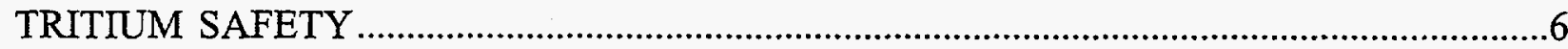

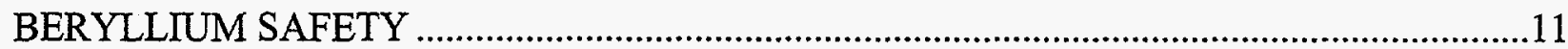

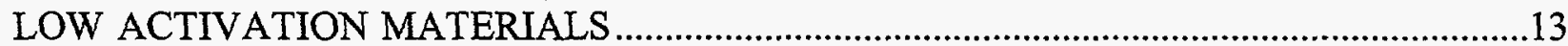

ACTIVATION PRODUCT CHEMICAL REACTIVITY, MOBILIZATION, AND

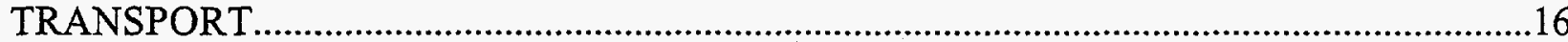

LIQUID METAL TECHNOLOGIES...........................................................................21

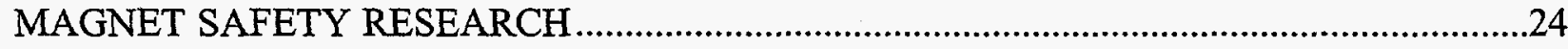

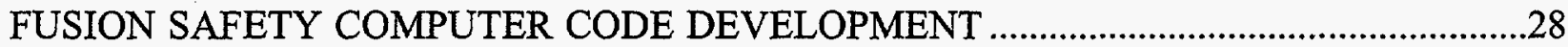

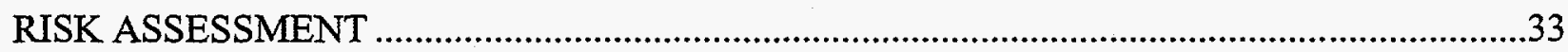

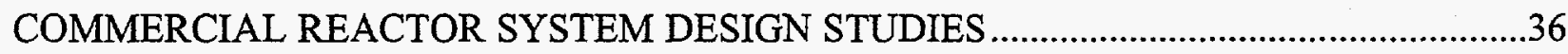

TOKAMAK FUSION TEST REACTOR AND TOKAMAK PHYSICS EXPERIMENT

SAFETY SUPPORT.

FUSION SAFETY STANDARD DEVELOPMENT. .45

APPENDIX A - ABSTRACTS OR SUMMARIES OF FUSION SAFETY PROGRAM PUBLICATIONS

APPENDIX B - ABSTRACTS OF FUSION SAFETY PROGRAM ITER ENGINEERING DESIGN FILES

\section{FIGURES}

Figure 1. Schematic of apparatus used in experiments on tritium release from beryllium. 
Figure 2. Model predictions of $\mathrm{Co}$ volatility from $\mathrm{Cu}$ alloy in steam compared with data.

Figure 3. MELCOR single-loop model schematic

Figure 4. Transient temperatures in ITER FW/SB component and hydrogen

produced for large ex-vessel LOCA

Figure 5. Sensitivity of hydrogen production to assumed first-wall failure temperature.

Figure 6. Criteria for safety-significant SSCs per DOE-STD -3009-94. 42

\section{TABLES}

Table 1. Tritium releases from ARIES IV

Table 2. Argon inventories at shutdown .38

Table 3. Defense-in-depth and worker safety SSCs

Table 4. Results of TPX risk assessment. 


\section{FUSION SAFETY PROGRAM ANNUAL REPORT FISCAL YEAR 1995}

\section{INTRODUCTION}

Fusion power has the potential to be an important energy source while remaining inherently safe with attractive environmental features. For the full safety potential to be realized, safety must be a consideration in all aspects of design and development. In addition to incorporating design features that will enhance the safety potential of fusion systems, this requires identifying safety and environmental concerns and developing materials and technology required to implement resolutions to those concerns.

In 1979, the U.S. Department of Energy established the Fusion Safety Program (FSP) to support safety in fusion development. The Idaho National Engineering Laboratory (INEL) is the designated lead laboratory, and in 1994 Lockheed Martin Idaho Technologies became the prime contractor for this program. The program focus is to develop safety and environmental goals for fusion energy production, to identify potential safety and environmental concerns in fusion devices and approaches to resolve these concerns, and to develop technical information, risk assessment methodologies, and safety-analysis computer codes required to verify that fusion facilities are safe and environmentally attractive.

Realization of fusion's potential will result from advances in plasma physics and technology that will enhance safety, environmental, and economic attractiveness. Plasma physicists are addressing issues of plasma disruptions, run-away electrons, emergency plasma shutdown, control of power levels, and reduction of tritium throughput. Priorities in the technology area include developing plasma-facing components and breeding blankets that are low in activation products and have minimal threats of chemical reactions the could produce explosive quantities of hydrogen. Ultimately, low activation materials will need to be developed for all components and structures exposed to fusion neutrons. Having appropriate and useful standards in place for the design of fusion facilities for safety is also of great importance. The FSP places a high emphasis on providing technical support and guidance in these critical areas.

International cooperation has become an increasingly important part of the FSP at the INEL. In addition to participating with Japan, the European Union, and the Russian Federation in the International Thermonuclear Experimental Reactor (ITER) project, we participate in activities of the International Energy Agency. Also, this year, we had a subcontract with Nizhny Novgorod State Technical University in Nizhny Novgorod, Russia for work on removal of activation products from $\mathrm{Li}-\mathrm{Pb}$ coolant.

Activities performed during this fiscal year include conducting experimental tests to develop data needed for safety analyses, developing computer codes and methodology 
for safety analyses, and participating in studies that support safety in fusion development. The FSP was also involved in safety support for the Tokamak Physics Experiment (TPX) and the Tokamak Fusion Test Reactor projects at the Princeton Plasma Physics Laboratory. Additionally, the FSP provided support to the ITER project by furnishing an individual to the ITER Joint Central Team and providing analysis and guidance in support of ITER safety studies. Another major activity this year has been leadership in the development of a DOE Technical Standard for safety of fusion test facilities.
The following sections summarize work completed under each of these activities by the INEL and participating organizations. Much of the work on ITER design studies and programmatic activities appears under the various technical areas in which the work was performed. Appendix A contains abstracts of publications based on work completed during FY-95. 


\title{
INTERNATIONAL THERMONUCLEAR EXPERIMENTAL REACTOR DESIGN AND REGULATORY SUPPORT
}

\author{
Researchers: D. A. Petti, L. C. Cadwallader, and S. J. Piet-INEL \\ T. Burr, J. G. Crocker, and J. C. Commander-Consultants
}

The Fusion Safety Program (FSP) leads the U.S. safety and environmental (SAE) effort for ITER. ITER participants are the U.S., the European Union, the Russian Federation, and Japan.

As part of the ITER effort, Dr. S. J. Piet is seconded to the ITER Joint Central Team (JCT). He is the Group Leader for Safety Analysis and Assessment (SAA). Dr. D. A. Petti is the Task Area Leader for Safety and Standards within the U.S. ITER Home Team.

\section{Major Accomplishments}

Dr. Piet and the SAA Group are responsible for the overall technical and management integration of ITER accident safety. The Group's major accomplishments have included establishing the basic ITER safety approach and high-level safety objectives; establishing the functional requirements for the major safety functions of radioactivity confinement, decay heat removal, and fusion power shutdown ${ }^{1,2}$; and completion of the Early Safety and Environmental Characterization Study (ESECS). ${ }^{3}$ ESECS is a pre-Environmental Impact Statement (EIS) type of document suitable for ITER prior to site selection. The ITER Technical Advisory Committee (TAC) now "recommends that the planned approaches be pursued so that ITER will be designed to be a safe fusion experiment." ${ }^{4}$ This technical and international convergence is a major step forward for ITER safety.
Dr. Piet coordinates the radioactivity confinement strategy, which is being tailored to ITER as an experimental fusion machine. It adapts elements from other technologies such as fission and chemical plants to fusion tokamaks. ESECS contains the most detailed examination of the ITER "source term" of any fusion study, building on help from several of the Home Team tasks, most notably the U.S. Home Team, hence from the Fusion Safety Program. The corresponding basic confinement strategy has been adopted by the project and (with help from the Home Teams) further optimization and detailed design implementation are underway.

The goal of our ITER design and regulatory support work in the Fusion Safety Program is to provide ITER safety and regulatory support to the JCT and to improve the safety of ITER by identifying key safety issues associated with the evolving ITER Engineering Design Activities (EDA).

The U.S. provided support to the JCT in developing the outline of the ITER Non-site Specific Safety Report (NSSR-1) based on the table of contents required by the U.S. Department of Energy's safety analysis report. $^{5}$ The U.S. safety team also reviewed the overall ITER R\&D program to determine those elements that have safety signficance and to illustrate steps that could be used to obtain regulatory approval for an experimental fusion machine like ITER. ${ }^{6}$ The basic approach recognizes that ITER will not have 
all the data needed for regulatory approval at the end of the EDA. Instead, a staged approach was recommended, in which the operating window is gradually increased as more operational data is obtained. For example, data obtained during the EDA plus commissioning test data is used to permit initial deuterium-deuterium (D-D) operation. Then the results from initial D-D operation are used as a basis for low power deuteriumtritium (D-T) operation. The results from low power D-T operation are used to obtain approval for full power D-T operation. This approach has precedence in the U.S. for experimental fission reactor facilities.

Support was also provided to the JCT in the area of structural safety. Because fusion components will be subjected to environmental conditions that are different than fission reactor components, critieria are needed to select a proper structural code for ITER components. Our work focuses on helping the JCT decide which part of the U.S. ASME Boiler and Pressure Vessel Code to be used for the ex-vessel components (e.g., cryostat, remote handling equipment, heat transport systems).

The U.S. ITER safety team provided substantial support for four major ITER safety and environmental meetings in October
1994, February 1995, June 1995, and October 1995. All ITER-related safety work being performed by the U.S. was reviewed by the ITER JCT at these meetings.

In addition to providing regulatory information for the ITER JCT, the U.S. ITER Task Area Leader for Safety and Standards was selected to be a member of the U.S. delegation to the ITER Special Review Group (SRG). The role of the SRG was to develop site requirements and site design assumptions that can be used by the Parties as they begin their siting activities. The SRG met three times between January and June 1995. Their final document was accepted by the ITER Council. The U.S. ITER Task Area Leader for Safety and Standards also made a number of presentations on safety and regulatory issues to U.S. groups such as the ITER Steering Committee U.S. (ISCUS), the U.S. Home Team, the 7th International Conference on Fusion Reactor Materials? and the DOE Office of Fusion Energy.

\section{Future Activities}

Our future efforts will be to continue work with the JCT on their regulatory and safety strategy for ITER and to help them complete the NSSR-1 safety documents. 


\section{REFERENCES}

1. S. J. Piet, H.-W. Bartels, C. W. Gordon, A. E. Poucet, and L. N. Topilski, "ITER Principal Safety Functions: Radiological Confinement, Heat Removal, and Shutdown," 16th Symposium on Fusion Engineering, Urbana, IL, September 30-October 4, 1995.

2. H.-W. Bartels, C. W. Gordon, D. Holland, S.J. Piet, A. E. Poucet, and L. N. Topilski, "Key Results in ITER Safety Analysis," 16th Symposium on Fusion Engineering, Urbana, IL, September 30-October 4, 1995.

3. Early Safety and Environmental Characterization Study, ITER Document S 81 RE 95-06-01 W 1.1, August 1995.

4. ITER Director and Joint Central Team Presenters, Presentations to The Technical Advisory Committee (TAC-8), 29 June - 7 July 1995, San Diego Joint Work Site, United States, TAC95-19, Oak Ridge National Laboratory.

5. L. C. Cadwallader, Proposed U.S. Annotated Table of Contents for the ITER Non Site-Specific Safety Report (NSSR), ITER/US/95/EN/SA-1, May 1995.

6. J. Crocker, R\&D Needs and Strategy to Support ITER Regulatory Approval, ITER/US/95/EN/SA-2, August 1995.

7. D. A. Petti, K.A. McCarthy, W. Gulden, S. J. Piet, Y. Seki, and B. Kolbasov, "An Overview of Safety and Environmental Considerations in the Selection of Materials for Fusion Facilities," Seventh International Conference On Fusion Reactor Materials, Obninsk, Russia, September25-29, 1995. 


\section{TRITIUM SAFETY}

\section{Researchers: T. J. Dolan, R. A. Anderl, G. R. Longhurst, and R. J. Pawelko-INEL}

Our tritium safety work is focused on ITER goals of keeping routine and accidental tritium releases within acceptable limits, thus avoiding the need for evacuation of the surrounding population. We are pursuing a broad spectrum of tritium-related studies, including continued development of the INEL tritium laboratory capabilities; plasma-driven permeation studies for plasma-facing materials (PFM); environmental tritium monitoring around the Tokamak Fusion Test Reactor (TFTR); applications of the TMAP4 code; and participation in the Tritium Plasma Experiment (TPE). Our efforts will help to facilitate ITER regulatory compliance and licensing.

\section{Major Accomplishments}

Tritium Research Laboratory. A new target/heater assembly and post-implantation thermal desorption system was designed for the ion-implantation system. This system will permit exposure of a heated specimen to the deuterium ion beam, rapid cooling of the specimen to ambient temperature to retain the implanted deuterium, and transport of the specimen, under vacuum, to an ultra-high vacuum chamber where the deuterium release behavior will be measured as the sample is subject to a thermal transient that simulates an accident scenario for ITER. The system is set for delivery and installation early in FY-96.

Collaboration with the TPE Experiment at LANL. Essential components of a thermal desorption system were assembled for use at the TPE that is located at the Tritium Systems Test Assembly (TSTA), Los Alamos National Laboratory (LANL). This system will be used to analyze tritium that is retained in specimens that are exposed to gaseous tritium atmospheres or to the TPE plasma.

\section{Deuterium Implantation/Permeation}

Studies. Deuterium implantation studies were conducted for $\mathrm{Be}, \mathrm{Cu}, \mathrm{CuCrZr}$-alloy, and $\mathrm{Cu} / \mathrm{Be}$-composite specimens. A detailed report of the work was published early in FY95. ${ }^{1}$ We summarized the results of the studies for $\mathrm{Cu}, \mathrm{CuCrZr}$-alloy and $\mathrm{Cu} / \mathrm{Be}$-composite specimens in an Engineering Design File prepared for the ITER Joint Central Team. ${ }^{2}$

The purpose of these studies was to perform scoping tests to obtain hydrogen/ tritium transport data for an ITER-relevant $\mathrm{CuCrZr}$ alloy of copper $(98.7 \% \mathrm{Cu}, 1.1 \% \mathrm{Cr}$, $0.1 \% \mathrm{Zr}$ ), pure copper, and bi-layered structures of copper on beryllium. As identified in the work scope for ITER Task $S$ 71 TT 49 (I56,NID-5b), these data are important to better define tritium permeation, retention and post-implantation mobilization issues in support of ITER safety studies. The approach taken here was to perform deuterium implantation/permeation experiments and post-implantation thermal desorption experiments on selected samples of the above materials. These experiments were supplemented by extensive materials 
simulate the measured re-emission and permeation results.

Permeation measurements were made for $\mathrm{CuCrZr}$ over the temperature range 425$500^{\circ} \mathrm{C}$, using a $3-\mathrm{keV} \mathrm{D}_{3}{ }^{+}$ion beam with fluxes of $6 \times 10^{19}$ to $7 \times 10^{19} \mathrm{D} / \mathrm{m}^{2} \mathrm{~s}$. Effective diffusivities and surface molecular recombination coefficients were derived by analyzing the experimental data. These results were used as input to TMAP4 calculations, in an effort to simulate the measured permeation data. A good match between the calculated and measured permeation curves was achieved for the cases studied. Arrhenius parameters that resulted from these analyses for the $\mathrm{Cu}$ alloy are:

$$
\begin{aligned}
& \text { Diffusivity } \\
& D=0.02\left(\frac{m^{2}}{s}\right) \exp \left(\frac{-1.2 e V}{k T}\right)
\end{aligned}
$$

Recombination coefficient

$$
K_{r}=2.9 \times 10^{-14}\left(\frac{m^{4}}{s}\right) \exp \left(\frac{-1.92 \mathrm{eV}}{k T}\right)
$$

Over the temperature range for this work, the diffusivities and surface molecular recombination coefficients for the $\mathrm{CuCrZr}$ were considerably smaller than those for pure copper. The reduced diffusivities provide evidence of deuterium trapping at bulk sites in the material, most likely at the $\mathrm{Zr}$. Permeation rates through the $\mathrm{CuCrZr}$ were about a factor of 8 higher than through copper, under the same experimental conditions.

Permeation measurements were made for OFHC-Cu over a similar temperature range, $425-500^{\circ} \mathrm{C}$, to provide confirmatory transport data representative of pure copper. Experimental conditions were similar to those described previously. Diffusivities and surface molecular recombination coefficients were derived from the data in the same way as for $\mathrm{CuCrZr}$, and TMAP4 calculations were done to simulate the measured permeation data. Arrhenius parameters derived from these analyses are:

$$
\begin{aligned}
& \text { Diffusivity } \\
& D=2.1 \times 10^{-6}\left(\frac{m^{2}}{s}\right) \exp \left(\frac{-0.52 \mathrm{eV}}{k T}\right)
\end{aligned}
$$

Recombination

$$
K_{r}=9.1 \times 10^{-18}\left(\frac{m^{4}}{s}\right) \exp \left(\frac{0.99 \mathrm{eV}}{k T}\right)
$$

Measured diffusivities were less than those predicted for pure copper. Differences between the calculated and measured permeation values indicate possible twodimensional and trapping effects in the experimental data.

We made various investigations to study the permeation of deuterium through $\mathrm{Cu} / \mathrm{Be}$ bi-layer material structures. Materials characterization and permeation measurements were made for specimens consisting of sputter-deposited copper coatings $(1-\mu \mathrm{m}$ and $5-\mu \mathrm{m})$ on high-purity $\mathrm{Be}$ foil specimens. These measurements indicated that, for specimen temperatures near $770 \mathrm{~K}$, there is a significant transport of $\mathrm{Be}$ from the substrate into the copper coating, with Be enrichment on the outer surface. At temperatures near $700 \mathrm{~K}$, for which successful permeation measurements were made, the $\mathrm{Be}$ transport into the coating was not as high, and the coating maintained copper as the dominant material element. Permeation measurements were made with the $3-\mathrm{keV} \mathrm{D}_{3}{ }^{+}$beam, (particle flux of $5.6 \times 10^{19} \mathrm{D} / \mathrm{m}^{2} \mathrm{~s}$ ) incident on the copper surface rather than the Be surface, to avoid the influence of beam-induced damage in the $\mathrm{Be}$ and to obtain information to test the 
influence of the $\mathrm{BeO}$ interface between the $\mathrm{Cu}$ coating and the $\mathrm{Be}$ substrate. The measured permeation data were compared with TMAP4 calculations in which the $\mathrm{Cu} / \mathrm{Be}$ specimen was modeled as a four-layer structure: $\mathrm{Cu}$ coating / $\mathrm{BeO}$ interface / $\mathrm{Be}$ bulk / $\mathrm{BeO}$ downstream surface layer. A reasonable simulation of the measured permeation data was achieved using currently recommended values for diffusivity and solubility in $\mathrm{Be}, \mathrm{BeO}$, and $\mathrm{Cu}$ and considering realistic thicknesses for the $\mathrm{BeO}$ layers. Systematic studies in which the $\mathrm{BeO}$ thicknesses were varied in the calculations demonstrated a high sensitivity of the calculated permeation rates to changes in the $\mathrm{BeO}$ layer thickness, especially at the $\mathrm{Cu} / \mathrm{Be}$ interface.

\section{Tritium and Helium Release from Irradiated Beryllium. In this work,} stepped-isothermal anneal experiments were conducted to investigate tritium and helium release behavior from beryllium irradiated to a fast neutron fluence of $5 \times 10^{22} \mathrm{n} / \mathrm{cm}^{2}$ in the Advanced Test Reactor (ATR). ${ }^{3}$ The experimental apparatus is shown schematically in Figure 1. In-line ionchambers and on-line quadrupole mass spectrometers were used for simultaneous analysis of the released gas concentrations in an Ar process stream flowing over a heated specimen. New information on gas-release kinetics and gas-species evolution was obtained from two experiments in which the temperature stepping was varied above $600^{\circ} \mathrm{C}$. For the experiment in which $200^{\circ} \mathrm{C}$ temperature steps were taken from $200^{\circ} \mathrm{C}$ to $1000^{\circ} \mathrm{C}$, greater than $99.8 \%$ of the available tritium and $52 \%$ of the helium $\left({ }^{3} \mathrm{He}\right.$ and ${ }^{4} \mathrm{He}$ ) were released in the step to $800^{\circ} \mathrm{C}$. The remaining helium was released in the step to $1000^{\circ} \mathrm{C}$. In contrast, for the experiment in which a $\mathrm{Be}$ specimen was heated in $50^{\circ} \mathrm{C}$ steps from $600^{\circ} \mathrm{C}$ to $800^{\circ} \mathrm{C}$, followed by a $200^{\circ} \mathrm{C}$ step to $1000^{\circ} \mathrm{C}, 86.3 \%$ of the available tritium was released with the specimen at $650^{\circ} \mathrm{C}$. For this experiment, $71 \%$ of the available helium was released in the step to $1000^{\circ} \mathrm{C}$ and higher, indicating that only about $29 \%$ of the helium was released during sample heating at $650^{\circ} \mathrm{C}$. In both cases the major gas release occurred as a "burst"; however, the maximum release rate was much smaller in the second experiment than in the first. The time dep endence of the gas-release rates was much different between the two experiments, with the release rates falling off much faster in the first experiment than in the second. We observed concurrent release of tritium and helium gases during the major release events for both experiments, providing direct evidence of these gases in helium bubbles in the irradiated beryllium. A quantitative analysis of the gases released during the $800^{\circ} \mathrm{C}$ step in the first experiment gave the following relative gas composition: $6 \% \mathrm{H}_{2}, 7 \%{ }^{3} \mathrm{He}, 2 \%$ $\mathrm{HT}, 81 \%{ }^{4} \mathrm{He}$, and $4 \% \mathrm{~T}_{2}$. The determination of the original inventories of entrapped tritium and helium $\left({ }^{3} \mathrm{He}\right.$ and $\left.{ }^{4} \mathrm{He}\right)$ in the Be specimens tested here are in good agreement with the measurements reported by Baldwin et al. ${ }^{4,5}$ and Beeston et al., 6 provided one takes into consideration the decay of tritium between their testing and ours.

Database Assessment. T. J. Dolan extended the survey of the literature begun the pervious year, adding information on tritium interactions with tungsten, considered as a candidate material for plasma-facing surfaces subject to high erosion. ${ }^{7}$

Tritium Source Term Analysis. G. R. Longhurst surveyed information available on tritium interactions with beryllium and 


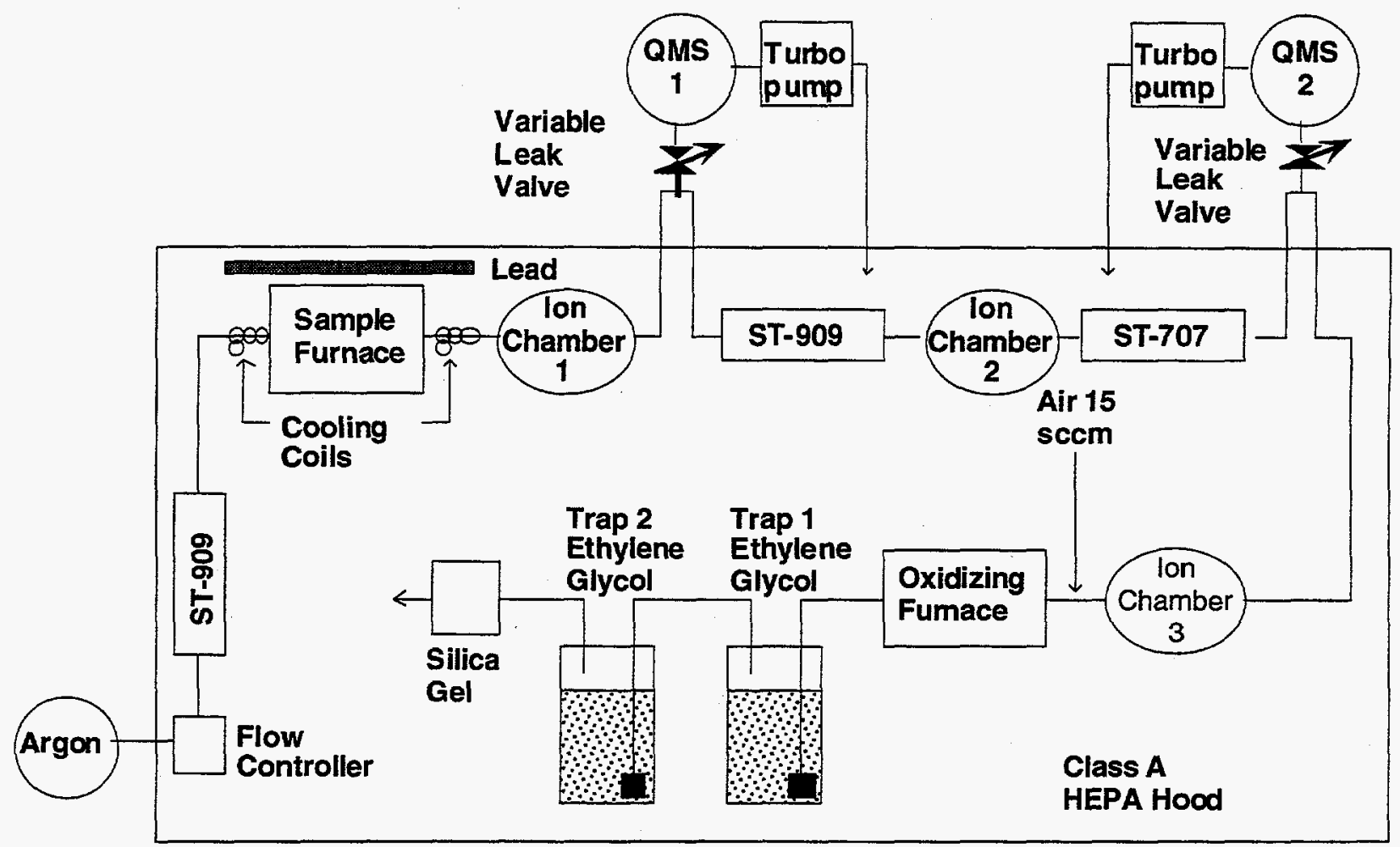

Figure 1. Schematic of apparatus used in experiments on tritium release from beryllium.

developed recommendations for modelling tritium transport processes in that material. ${ }^{8}$

TMAP4 Code. Although no development activity was performed on TMAP4 this year, we provided the code to a number of persons working on ITER and related problems. It has also been used at the INEL in non-ITER applications this past year. We did identify a number of improvements we wish to make to the code when resources become available.

\section{Future Activities}

In general, our work will focus on providing support for the Safety and Environmental Tasks of the ITER project.
The tritium laboratory facility upgrade will continue. Implantation experiments will make use of the new facilities to examine what happens to multi-layer materials and/or amorphous mixtures representative of ITER plasma-facing components, in coordination with experiments at the TPE. We will conduct experiments and TMAP4 analyses that complement the experiments at TPE. We will provide equipment and manpower to do thermal desorption spectroscopy of specimens irradiated in TPE and in fission reactors. 


\section{References}

1. R. A. Anderl, Deuterium Implantation Studies for Beryllium, EDF No. ITER/94/US/ TE-SA21, October 12, 1994.

2. R. A. Anderl, R. J. Pawelko, and M. R. Hankins, Deuterium Implantation Studies for $\mathrm{Cu}$, $\mathrm{CuCrZr-alloy,} \mathrm{and} \mathrm{Cu/Be} \mathrm{Composites,} \mathrm{ITER/US/95/TE/SA-4} \mathrm{(Rev.} \mathrm{1),} \mathrm{May} \mathrm{5,} 1995$.

3. R. A. Anderl, J. D. Baker, G. L. Bourne, and R. J. Pawelko, "Tritium and Helium Release from Irradiated Beryllium," Fusion Technology, 28, 1995, pp. 1114-1119.

4. D. L. Baldwin et al., "Tritium Release from Irradiated Bery llium at Elevated Temperatures," Journal of Nuclear Materials, 179-181, 1991, pp. 329-334.

5. D. L. Baldwin, "Tritium Release Studies of Irradiated Beryllium," Workshop on Beryllium for Fusion Applications, Karlsruhe, Germany, October 4-5, 1993, Rep ort KfK 5271, December 1993.

6. J. M. Beeston et al., Gas Retention in Irradiated Beryllium, U.S. DOE Report EGG-FSP9125, Idaho National Engineering Laboratory, June 1990.

7. T. J. Dolan, ITER In-Vessel Tritium Source with Graphite and Tungsten Plasma Facing Components, ITER/US/95/TE/SA-5 (Rev. 1), May 4, 1995.

8. G. R. Longhurst, T. J. Dolan, and M. J. Mulock, "Modeling Tritium Processes In PlasmaFacing Beryllium," Fusion Technology, 28, October 1995, pp. 1217-1222. 


\section{BERYLLIUM SAFETY}

\section{Researchers: G. R. Longhurst, R. A. Anderl, and T. J. Dolan-INEL}

Beryllium is presently contemplated for use in fusion facilities as a plasma-facing material and as a neutron multiplier in tritiumbreeding blanket applications. There are yet several questions regarding the use of beryllium that remain to be answered, many of them connected with safety issues. Some of these issues are the response of beryllium mechanical properties to neutron irradiation, tritium trapping and release characteristics, and the consequences to surface structure of interactions with the plasma. These are among the safety issues we have been investigating. Work on chemical reactions and tritium retention characteristics is addressed in other sections.

\section{Major Accomplishments}

The main activity this year was the organization and conduct of the 2nd IEA International Workshop on Beryllium Technology for Fusion. This workshop was actually the fourth workshop on this topic to be held, but it is only the second with IEA sponsorship. The first was held in 1988 at the INEL. A second was held at Clearwater Beach, Florida in November 1991 in conjunction with the Fourth International Conference on Fusion Reactor Materials. In 1993 the first such workshop with IEA sponsorship was held in Karlsruhe, Germany. This year, the meeting was held September 68, 1995 at Jackson Lake Lodge, Wyoming. This year for the first time there was a substantial participation by colleagues from the Russian Federation. A total of 42 papers were presented in seven sessions over the course of three days. There was also a "Town Meeting" in which conferees were able to express views concerning important issues to be addressed by future beryllium reserarch. We were pleased that the proceedings were published and distributed in less than four weeks following the workshop. ${ }^{1}$

\section{Future Activities}

Further work on beryllium will be combined with work in other areas. We hope to receive the samples from the EBR-II irradiations in early 1996 . They will used mainly for chemical reactivity combined with tritium release measurements. The samples that were irradiated in the Fast Flux Test Facility (FFTF) are still awaiting funding of the removal of the samples from their canisters. Work planned to examine the effects of neutron irradiation on mechanical properties of beryllium is being deferred, pending delivery of the FFTF samples. 


\section{Reference}

1. G. R. Longhurst, Proceedings of the 2nd IEA International Workshop on Beryllium Technology for Fusion, September 6-8, 1995, Jakson Lake Lodge, Wyoming, CONF-9509218, September 1995, Idaho National Engineering Laboratory. 


\section{LOW ACTIVATION MATERIALS}

\section{Researchers: K. A. McCarthy, W. J. Carmack, G. R. Smolik, and P. K. Gorman-INEL}

Fusion power has the potential to be a safe and environmentally friendly energy source. Through the use of "low activation materials," hazards from accidental release of radioactive materials can be limited, and waste disposal problems minimized. ITER will probably be built from well-known materials such as stainless steel, which is not a low-activation material. Thus, in addition to the safety work for ITER materials, we must look into the safety and environmental aspects of materials that can be used for a DEMO reactor and commercial power reactors. This task supports work in the safety and environmental aspects of low-activation materials.

\section{Major Accomplishments}

We continued work in the area of vanadium recycling. We investigated the potential for recycling vanadium alloys irradiated in a fusion power reactor. ${ }^{1}$ This study was conducted as a preliminary scoping activity to show that the accident hazard of recycled fusion reactor materials can be reduced, resulting in easier and safer handling during refabrication. We focused on the V$5 \mathrm{Ti}-5 \mathrm{Cr}$ (vanadium with $5 \mathrm{wt} \%$ titanium and 5 $\mathrm{wt} \%$ chromium) alloy. The processes applied in this investigation are also applicable to the $\mathrm{V}-4 \mathrm{Ti}-4 \mathrm{Cr}$ alloy that has recently been identified by the U.S. as the preferred alloy for use in a commercial fusion power plant. As a structural material in a fusion power facility, vanadium will undergo exposure to highenergy neutrons, inducing radioactivity in the material. Recycling rather than disposing of the irradiated vanadium would be beneficial since large quantities of vanadium will be needed in the fusion power reactor. Electroslag remelt was chosen for processing vanadium for a number of reasons. The electroslag process has low metal evaporation loss due to the coverage provided by the slag pool. ${ }^{2}$ The electroslag process supports hightemperature chemical reactions between the slag and vanadium alloy.

Four candidate transmutation products ( $\mathrm{Ca}, \mathrm{Y}$ - to simulate $\mathrm{Sc}, \mathrm{Mn}$, and $\mathrm{Ar}$ ) were chosen for investigation because of their high contribution to early off-site dose during hightemperature oxidizing accident conditions. ${ }^{3}$ The removal of these transmutation products will help demonstrate the promise of recycling vanadium alloys in fusion reactor applications.

A typical electroslag remelt experiment consisted of the following steps. The bottom of the furnace crucible was lined with a material with a similar composition to that of the electrode material. Dendritic vanadium was used as the starter material during the first test. All of the following tests were conducted using a pad cut from the bottom of the ingot from the previous run. The electrode was positioned to just touch the pad material. The slag material was then poured around the electrode on top of the starter pad. The furnace was closed and evacuated and then repressurized to $30 \mathrm{kPa}(0.3 \mathrm{~atm}$.) with weldinggrade helium gas. Power was applied, striking an arc between the vanadium alloy electrode 
and the pad material at the bottom of the crucible. The electrode was withdrawn to allow the slag to become molten. A good slag pool, i.e., one that completely covered the underlying vanadium starting material, was developed before the electrode was fed into the pool.

We observed that as the electrode was fed into the pool, drops of vanadium alloy melted off of the end and dropped through the slag. Reactions to remove transmutation isotopes appeared to occur both at the electrode surface and within the slag pool. An ingot of the vanadium alloy solidified on the bottom of the crucible due to the cooling action of the watercooled copper crucible. When most of the electrode was melted, the power was turned off and the furnace was allowed to cool. Once cool, the copper crucible was removed and the vanadium alloy ingot and slag material was extracted from the crucible.

The chemical analyses for these ingots showed some interesting trends. About $40 \%$ of the manganese was removed from the electrode material. Over $99 \%$ of the argon initially present was removed from the alloy in the first melt, and approximately another $50 \%$ reduction in argon content was obtained in a second melt of the material. Ninety-nine per- cent of the yttrium and $90 \%$ of the calcium were removed in the first run.

Chemical thermodynamic equilibrium calculations involving the molten alloy and slag systems are not effective in predicting the removal of some transmutation isotopes such as manganese. Additional research would be needed to understand the mechanisms involved in the refining processes. However, this study has shown that some critical isotopes in accident safety can be removed from irradiated vanadium by electroslag remelting. Other applications of this method have shown it is suitable for scale-up to handle large tonnage melts. Therefore, this process could be a viable method to reduce the lead time for recycling the material back into service in a fusion facility.

\section{Future Activities}

Work in this area will be minimal due to the pressure to use funds for ITER-relevant work. Activity will be limited to participation in a low-activation materials panel, if such a panel is assembled. Future work will be needed to investigate the removal of transmutation isotopes that affect the material properties of vanadium alloys. 


\section{REFERENCES}

1. W. J. Carmack, G. R. Smolik, K. A. McCarthy, and P. K. Gorman, Slag Remelt Purification of Irradiated Vanadium Alloys, INEL-95/00324, July 1995.

2. A.J. Singh, High Temperature Materials and Processes, 9, 1990, p. 305.

3. G.J. Butterworth, K.A. McCarthy, G.R. Smolik, and C.B.A. Forty, "Safety and Environmental Aspects of Vanadium Alloys," Journal of Nuclear Materials, 212-215, 1994, pp. 667672. 


\title{
ACTIVATION PRODUCT CHEMICAL REACTIVITY, MOBILIZATION, AND TRANSPORT
}

\author{
Researchers: $\quad$ K. A. McCarthy, G. R. Smolik, D. L. Hagrman, \\ W. J. Carmack, R. A. Anderl, M. A. Oates, R. J. Pawelko, \\ K. Messick, J. E. O'Brien, and D. A. Petti-INEL
}

Deuterium-tritium 14-MeV fusion neutrons will produce activation products in materials. Since activation products are an accident concern, we are examining the behavior of activation products under accident conditions. We are studying the formation and transport of mobile activation products and chemical reaction rates for potential energy release or hydrogen production. We are focusing on materials for the divertor, first wall, blanket, and shield, and their behavior at high temperatures during accidents and in oxidizing gases like air and steam.

\section{Major Accomplishments}

We have continued developing the database for the mobilization and transport of various elements from candidate materials for the first wall and plasma-facing components for ITER and commercial fusion reactors. We completed construction of a scaled-up aerosol source for use in mobilization and transport tests. Modeling the mobilization and transport process is increasing our understanding of the mechanisms involved. We began development of an apparatus to measure the chemical reactivity of irradiated $\mathrm{Be}$ in steam. This apparatus must be more sensitive than the one we used previously to allow accurate measurements on the smaller samples we will test.

\section{Activation Product Mobilization Task.} During this fiscal year, the mobilization task focused on three areas: (a) construction of a scaled-up aerosol source to be used in mobilization and transport tests, (b) volatility modeling, and (c) Inconel mobilization in air.

We developed a moderate-scale, high-temperature aerosol source facility, FAST. (Fusion Aerosol Source Test) to address important safety issues related to the mobilization, transport and confinement of toxic and activated aerosols in fusion facilities. ${ }^{1}$ This facility will be used to provide data on the mobilization of ITER relevant materials (316SS, Cu, W) at temperatures of 400$1200^{\circ} \mathrm{C}$. Volatility data will be compared with results reported by McCarthy et al.,2 in smallscale experiments (VAPOR Facility). The moderate-scale facility provides approximately a two order-of-magnitude increase in active surface area and aerosol production rate. These tests will allow improved detection limits relative to the smaller experiments and permit more detailed characterization of produced aerosols, both in terms of physical characteristics such as particle size distribution, total mass, and composition. Although this source was originally planned to be used as an aerosol source in a medium-scale aerosol confinement test facility, ${ }^{3}$ such a facility now has lower priority among ITER safety tasks. As a result, the benefit of this facility will be to (a) examine scaling effects relative to the earlier experiments and (b) obtain better data at low temperature $\left(<500^{\circ} \mathrm{C}\right)$ where detection limits have hampered previous mobilization and transport experiments. 
Our volatility modeling effort concentrated on the mobilization of $\mathrm{Zn}, \mathrm{Co}$, and $\mathrm{Fe}$ from a $\mathrm{Cu}$ alloy. ${ }^{4}$ Analysis of the data from the VAPOR tests and the associated modeling showed that the primary means of mobilization of zinc, cobalt, and iron in steam is volatilization. The models imply that surface concentrations of hydrogen reduce the volatilization flux by reducing the equilibrium vapor pressure of the evaporating hydroxide species. Figure 2 shows the modeling results compared with experimental results for Co volatility in steam. The mass flux of $\mathrm{Co}$ is orders of magnitude lower than that of $\mathrm{Zn}$. This means the hydrogen produced by the zinc reaction is much greater than the hydrogen produced by the Co reaction. The difference between the 1and 5-hour calculations is not caused by variations in the rate of diffusion of Co to the alloy surface, but rather by variations in the hydrogen production by zinc. In longer tests at higher temperatures, the reduction of the rate of volatilization of $\mathrm{Zn}$ reduced the hydrogen concentration present at the alloy surface. This reduction increases the equilibrium concentration of cobalt hydroxide. The primary means of mobilization of zinc, cobalt, and iron in air is stochastic oxide spalling as temperature is reduced.

We tested samples of Inconel 625 in flowing air over the temperature range 600 $1200^{\circ} \mathrm{C}$ to evaluate the mobilization of various elements during oxidation. 5 Inconel 625 has a higher chromium content, ( $21 \mathrm{wt} \%$, compared to $16-18 w t \%$ ) than found in the austenitic stainless steels previously tested for fusion applications. This higher chromium content resulted in the development of a protective chromia scale. The chromia scale remained

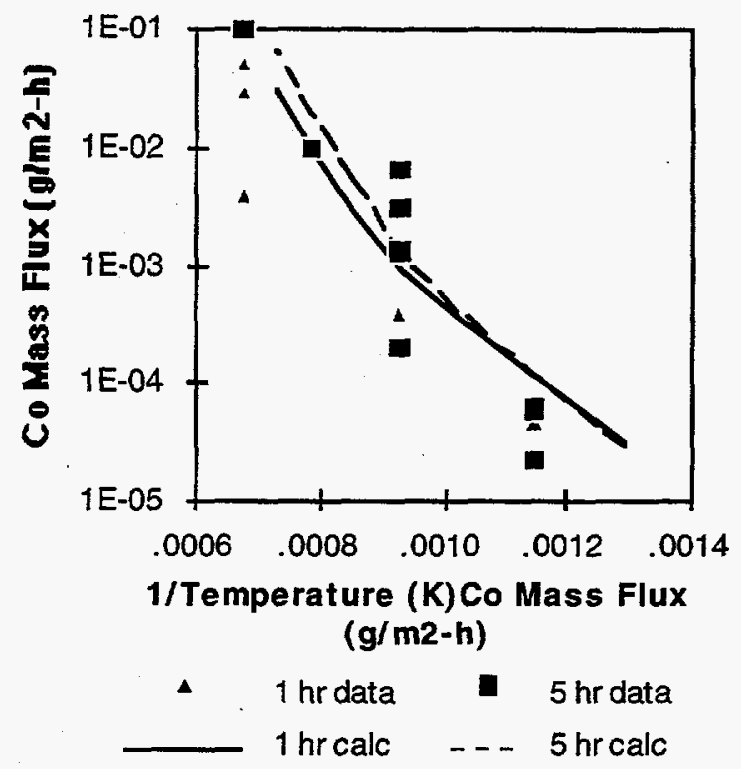

Figure 2. Model predictions of Co volatility from $\mathrm{Cu}$ alloy in steam compared with data.

protective for up to 5 hours at $1200^{\circ} \mathrm{C}$. The amount of oxide formed on Inconel 625 at $1200^{\circ} \mathrm{C}$ was less than one-tenth of that formed on 316 stainless steel. In addition, smaller amounts of the oxide scale spalled from the Inconel 625 (less than $2 \%$ compared to over $80 \%$ for 316 stainless steel). Also, fewer of the spalled oxide particles were sufficiently small to remain airborne and transportable. The low mobilization rates measured in this study indicate that for temperatures of up to $1200^{\circ} \mathrm{C}$ and times of up to 5 hours, mobilization of activation products from Inconel 625 is less than mobilization occurring from austenitic stainless steels with 16-18 wt \% chromium.

Aerosol Transport Task. During this fiscal year, the aerosol transport task focused on two areas: (a) transport of oxidized 316 stainless steel and copper alloy concentrating on spalled oxide transport, and (b) modeling transport of aerosols from PCA steel. 
We carried out a series of experiments to provide more specific information about the time required for oxide spalling in 316SS and copper alloy, and about the size distribution of the spalled oxides. ${ }^{6}$ A test system was set up with a valve to control the flow of the test gases, air or steam, during the cool-down period of the experiment. The flow could be directed through a cascade impactor or be diverted to another filter during cool down. This allowed us to establish the time at which oxide spalling predominantly occurred. In addition to the cascade impactor, particle sizes were determined by screening and with a particle size analyzer.

We found that some oxide spalling can occur during the growth stages of the oxide scale during the isothermal portion of the exposures. However, most of the spalling, probably 80 $\%$, occurs during cool down. In addition, we found that generally the spalled oxide was composed of fairly large particles. More than $80 \%$ were over $250 \mu \mathrm{m}$ in size. Only 0.5 and $1.5 \%$ of the mass of spalled oxide were below $10 \mu \mathrm{m}$ and $20 \mu \mathrm{m}$, respectively. Even fewer particles of these small sizes were generated when oxide spalled from the copper alloy after exposures in air. Larger amounts of such particle sizes were formed when the copper alloy was exposed to steam. The percentages of spalled oxide below $10 \mu \mathrm{m}$ and $20 \mu \mathrm{m}$ were 2.3 and $5.7 \%$, respectively. These experiments show that previous mobilization measurements have been largely made of up larger particles, i.e., 10 to $250 \mu \mathrm{m}$. These particles are too large to be transported as aerosols and will settle, be attracted to system walls, or be easily filtered. This indicates that our dose calculations based on total mobilization are conservatively high since most of the aerosol will not be transported out of the confinement.
Analysis of transport experiments with PCA steel in the VAPOR facility showed that there are likely to be two kinds of aerosol particles present: homogeneously nucleated particles and spalled particles. ${ }^{7}$ The differences in the nature of these particles will produce noticeable differences in aerosol behavior. In air, molybdenum oxide is volatilized from the steel surface during $1200^{\circ} \mathrm{C}$ exposures and condenses to form an aerosol consisting of very small particles. Manganese and cobalt are present as oxides at the steel surface. They do not volatilize significant amounts of vapor because of the low equilibrium vapor pressures of these oxides. However, we believe that a small portion of the oxide spalling consists of particles small enough to be mobile. We also believe, based on tentative evidence from electron microscopy and calculations, that the spalling in air is mostly during cooldown. For the tests in air at $1200^{\circ} \mathrm{C}$, we conclude that the mass volatilized was similar in amount to the mass spalled, but almost all of the mobile dose-relevant elements, cobalt and manganese, were associated with spalled particles in a 5-hour PCA test $\left(1000^{\circ} \mathrm{C}\right.$ in steam $)$.

In steam, iron, manganese, and cobalt are volatilized from samples at $1000^{\circ} \mathrm{C}$. The volatilized material is mostly $\mathrm{Fe}(\mathrm{OH})_{2}$ with some $\mathrm{Mn}(\mathrm{OH})_{2}$, and $\mathrm{Co}(\mathrm{OH})_{2}$. However, very small amounts of the oxides of the metals may be formed when these species move away from the steel surface, cool, and give off a water molecule. The oxides have such low vapor pressures that they may nucleate particles to form an aerosol in the absence of aerosol particle seeds of some other species. Our modeling calculations found that this did not happen in the VAPOR experiment 
Chemical Reactivity Task. Our primary focus in this area has been to develop a facility for testing chemical reactivity of irradiated beryllium. We will be testing samples irradiated in EBR-II. ${ }^{8}$ These samples are smaller than what we normally test. Thus reducing detection limits is very important in this task. Hydrogen production will be measured directly and also through weight gain. The direct measurement will be done with a mass spectrometer. The detection limits in the new apparatus are over an order of magnitude lower than those in the original apparatus.

A new experimental system is under development for measuring the chemical reactivity of irradiated beryllium that is exposed to steam. The system consists of a linear assembly of the following: a steam generator, a quartz-tube reaction chamber heated by a tube furnace, two Friedrich condensers to remove steam from the process line, a low-temperature trap to remove residual water vapor from the process line, a quadrupole mass spectrometer (QMS) that analyzes the gas composition in the process line through a sampling valve, an in-line ion chamber for measurement of gaseous tritium, an oxidizer to convert tritium to the oxide form, and an ethy lene gly col trap to collect the tritium oxide. The system operates with an argon carrier gas. Primary gas standards are used to calibrate the QMS analysis instrumentation. Much of the system will be located in an inert-gas glove box for the measurements on irradiated bery llium.

\section{Future Activities}

The primary focus of our work will continue to support the ITER project. We will issue comprehensive reports on our recent steel, copper alloy, and vanadium alloy tests. Our testing will focus on areas where more data are needed, with a near-term effort directed toward providing data for ESECS. We will begin testing in the scaled-up aerosol source test facility, FAST (Fusion Aerosol Source Test). We will continue our modeling efforts to support our experimental work. We will begin testing in our apparatus designed for measuring chemical reactivity of irradiated beryllium. Shakedown tests with steel and nonirradiated beryllium will be done before testing of irradiated specimens begins. 


\section{REFERENCES}

1. W. J. Carmack, J. E. O'Brien, and J. L. Hunt, The Design of a Medium-Scale Aerosol Source for ITER Safety Studies, ITER/US/95/TE/SA-25, September 15, 1995.

2. K. A. McCarthy, G. R. Smolik, and S. L. Harms, A Summary and Assessment of Oxidation Driven Volatility Experiments at the INEL and Their Application to Fusion Reactor Safety Assessments, EGG-FSP-11193, September 1994.

3. D. L. Hagrman and D. A. Petti, Experiment Requirements for a Moderate Scale Fusion Reactor Aerosol Confinement Test Facility, ITER/US/94/EN/SA-9, May 1994.

4. D. L. Hagrman, Models for Mobilization of Zn, Co, and Fe from Copper Alloy, ITER/95/US/TE/SA-2, February 6, 1995.

5. G. R. Smolik and K. Messick, Mobilization During the Oxidation of Inconel 625, ITER/95/US/TE/SA-27, September 18, 1995.

6. G. R. Smolik and K. Messick, Transport Investigation of Oxidized 316 Stainless Steel and Copper Alloy, ITER/95/US/TE/SA-26, September 18, 1995.

7. D. L. Hagrman, Modeling Transport of Aerosols from PCA Steel Alloy, ITER/95/US/TE/SA11, May 12, 1995.

8. A. M. Ermi, Preliminary Report on the Irradiation Parameters for the EBR-II COBRA-1A2 Test, Westinghouse Hanford Company, November 1994. 


\section{LIQUID METAL TECHNOLOGIES}

\section{Researchers: K. A. McCarthy-INEL, A. V. Beznosov-NNSTU, L. S. Nelson, E. J. Gracyalny, M. L. Corradini-UW}

The liquid metal chemical reactions program has studied hazards associated with liquid lithium and lithium-lead considered for use as tritium-breeding materials and with various liquid metals considered for use as a coolant. These hazards include hydrogen production, overpressure, and materials volatilization through chemical heat generation.

This task supports both near-term fusion (ITER) and commercial fusion facilities. Liquid metals will be present in ITER in test modules, with the possibility of their being used as a coolant or breeder in the blanket/first wall.

\section{Major Accomplishments}

Our work at the University of Wisconsin this year focused on two major activities. We completed a series of lithium-lead/water shock tube experiments using the lithium-lead we produced last fiscal year. The second activity was the modification of a module for the code MELCOR to allow for modeling of a wider variety of liquid metal/water interaction scenarios. In addition to this work, we investigated the possibility of on-line bismuth and polonium-210 removal at the Nizhny Novgorod State Technical University in Nizhny Novgorod, Russia.

\section{Lithium-Lead/Water Chemical Reac- tivity Task. Because water-cooled molten $83 \mathrm{a} / \mathrm{o} \mathrm{Pb}-17 \mathrm{a} / \mathrm{o} \mathrm{Li}$ eutectic alloy is being con- sidered for use in the blanket for nuclear fusion applications, it is important to under-}

stand the interactions that might occur if this alloy were inadvertently to contact liquid water. We investigated the behavior of the molten alloy at $600^{\circ} \mathrm{C}$ when impacted with a vertical $2.4 \mathrm{~m}$-tall column of water at $25^{\circ} \mathrm{C}$ or $60^{\circ} \mathrm{C}$. The behavior was compared with similar impacts of $25^{\circ} \mathrm{C}$ or $60^{\circ} \mathrm{C}$ water on molten lead at $600^{\circ} \mathrm{C}$. Also, two shakedown runs were performed with empty crucibles. This is a follow-on to the small-scale experiments first performed by Herzog in 1987.1

Multiple pressure spikes were produced with the $\mathrm{Pb}$, while essentially only one initial pressurization followed by a few strongly damped minor peaks were observed with the alloy. $\mathrm{H}_{2}$ and aqueous solutions of $\mathrm{LiOH}$ were generated with the alloy, but not with the lead. Also, an aerosol with an acrid odor was detected in the gases vented about 6 minutes after the alloy-water interactions. The debris recovered after the water impacts on both $\mathrm{Pb}$ and the alloy was highly porous.

The amount of $\mathrm{H}_{2}$ estimated by quadrupole mass spectrometry is about $20 \%$ less than that estimated on the basis of titration of the $\mathrm{OH}^{-}$ion. This observation was unexpected and is probably due to sampling of the gases within minutes of the interaction, before the melt had cooled completely, while the solutions for titration were collected many hours after the system had equilibrated both thermally and chemically, allowing for oxidation. 
MELCOR Module Development Task. We added fusion materials capabilities to the Fuel Dispersal Interaction (FDI) module of MELCOR and verified its successful implementation. This work accomplished three tasks. First, the materials gallium, lead, and lithium-lead were added to the materials database in the MELCOR computer code. Next, the FDI module underwent modification to access these new materials. Finally, the lowpressure melt ejection sequence of the FDI module underwent considerable enhancement to make it a truly "stand-alone" package. This means that the FDI module no longer requires I/O with the other packages of the MELCOR computer code. This ability significantly increases the module's flexibility and will greatly ease any future adaptations of the module to study phenomena inherent to ITER or other fusion reactors.

\section{Polonium/Bismuth Removal From} Lithium-Lead. An extensive data search was made to determine potential bismuth and polonium removal methods, and, based on this data search, a method for removal of polonium was developed and tested experimentally. We determined that bismuth removal is not economically feasible. Experiments were conducted with a lead-bismuth eutectic, keeping in mind that these results should be applicable to a lithium-lead system. ${ }^{2}$ The removal method chosen minimizes equipment, circuits, and systems, because it is simultaneously capable of removing impurities such as corrosion and erosion products, extracting tritium, and assisting in the formation of electroinsulating and protective coatings on coolant tubes. This study investigated only the polonium removal capability.

The method chosen was based on the formation of a two-component flux consisting of liquid metal and protective gas (less than $5 \%$ of the total volume). This flux is circulated through pipelines and circuit equipment. The gas phase enriched in impurities is separated on the free surface of the coolant. The gas with impurities is removed to tanks for further processing or burial of impurities. Scoping experiments with a lead-bismuth eutectic and tellurium to simulate polonium showed that about $16 \%$ of the total mass of impurities was trapped in the filter, $23 \%$ accumulated on the wall of the discharge pipe, $30 \%$ at the place of the cap connection with the discharge pipe, with the remainder probably at the walls of the cavity and in the gas meter. Further experimentation is needed to refine the method, but the method showed promise.

\section{Future Activities}

Our primary activity will be the support of the ITER test module program. We will continue to make modifications to the MELCOR code, primarily, modifications to allow analysis of scenarios with pure lithium/water chemical reactions. We will apply the MELCOR code to provide information for the safety case for the test module program. 


\section{References}

1. J. P. Herzog, Lithium-Lead/Water Interactions: Experiments and Analysis, UWFDM-791, March 1989.

2. A. V. Beznosov, Analysis of Bismuth and Polonium Impurities Removal Methods From LeadLithium Coolant and Circuit as Applied to the Thermonuclear Reactor Blanket Cooling System, Nizhny Novgorod State Technical University, October 1995. 


\section{MAGNET SAFETY RESEARCH}

\section{Researchers: J. Stephen Herring and Lee C. Cadwallader-INEL}

Fusion reactors will require large sets of superconducting magnets, storing over $100 \mathrm{GJ}$ of electrical energy. The safe and reliable operation of these magnets is critical for both near-term experiments and for the eventual acceptance of commercial fusion reactors.

Operation of the superconducting magnet system poses a safety concern when a failure such as an arc or structural movement threatens the confinement of radioactive or toxic materials. The Fusion Safety Program aids magnet designers through analyses that indicate accident initiators and the consequences of individual component failures.

\section{Major Accomplishments}

Work on the safety of superconducting magnets focused on the development of a code for modeling the movement of ferromagnetic objects inadvertently left near the reactor. Additional work investigated expected failure rates in superconducting components proposed for International Thermonuclear Experimental Reactor (ITER).

\section{Movement of Ferromagnetic Objects.}

During FY-95, the Fusion Safety Program developed a computer code which determines the trajectory of a ferromagnetic object in the ex-vessel poloidal field (PF). An Engineering Design File (EDF) ${ }^{1}$ was published describing the workings of this code.

The EDF contains the development and initial applications of a program, FERMAG, which calculates the trajectory of a ferromag- netic object in the fringe poloidal fields surrounding ITER.

In ITER, the impact of an accelerated ferromagnetic object could damage vacuum windows, small manifolds, instrumentation and electrical connections. Ferromagnetic objects in the field gradient will also experience repeated lateral forces, whether or not they are free to be accelerated. Finally, injury to workers is possible if the area surrounding the magnets is occupied.

The EDF first derives the expressions for forces on ferromagnetic objects as:

$$
\mathbf{F}=\frac{\chi V B}{\mu_{o}} \nabla|\mathbf{B}|
$$

and expressions for the change in direction and velocity as a result of inelastic impacts with specified barriers surrounding the reactor. Ferromagnetic saturation and gravity are included in determining the trajectory of the object. The program makes use of the elliptic integral subroutine described in an earlier EDF. $^{2}$

During maintenance and operation of ITER, it is possible that small hand tools, bolts, construction detritus and other ferromagnetic objects may be inadvertently left in areas surrounding the cryostat. When the poloidal field magnets are energized, the field gradients in the areas surrounding the reactor may be sufficient to move those objects into areas of still stronger field gradients and finally to accelerate the unrestrained objects toward the other boundaries of the cryostat. Operation of much smaller Magnetic Reso- 
nance Imaging (MRI) coils has led to instances where compressed oxygen bottles, gurneys, and even fork-lift tines have been accelerated into regions of stronger field. ${ }^{3}$ Discussions with MRI personnel have revealed that maintenance and rescue personnel can also inadvertently introduce ferromagnetic objects into regions of high field gradients. ${ }^{4}$

Ferromagnetic materials are widely used in industrial settings. Carbon steel, structural steel, many high strength fasteners and ferritic stainless steels are ferromagnetic. Austenitic stainless steel is not ferromagnetic. Ferromagnetic materials have permeabilities greater than that of vacuum by factors from 10 to $10^{6}$.

Barriers Surrounding the Reactor. The program allows for the designation of up to 100 points that define barriers surrounding the reactor. The barriers are cylindrically symmetric (i.e., the barriers are sections of cones and circular cylinders), but do not have to be continuous. Thus a ring (e.g., external coil) surrounding a cylinder can be defined. In defining the barrier surfaces, it is important that the points be input in an order such that, as one proceeds from one point to the next the solid barrier is always on the left. This convention is necessary to correctly compute the angle at which the object rebounds from the various barriers. It is also important that the initial location of the object not be exactly on one of the barrier surfaces since the direction solution becomes indeterminate in that case.

The results of the nine cases are summarized in the EDF. ${ }^{1}$ The most severe impacts result from tools left under the tokamak. Hand tools or bolts reached an velocity of 80 $\mathrm{m} / \mathrm{s}$ at impact. We assume in all cases that the object is released into a steady-state magnetic field, as would be the case if it were a socket on a bolt head or a loose bolt coming out of a bolt hole. If the object is lying unrestrained on a surface, the smaller fields during current ramp up would dislodge it earlier and the impacts would be less severe.

Appendices to the EDF contain:

1. A complete listing of the FERMAG code, including a listing of all variables and their units.

2. Input files and output files in the initial application of the code to the ITER exvessel fields.

3. A comparison of the results of the code with the forces on a ferromagnetic object as predicted by the dipole approximation.

4. A comparison of the fields and vector potential immediately surrounding the winding pack as determined in a singleturn with the same parameters calculated by a model where the coil contains 100 turns.

ITER Failure Rate Data Collection. INEL researchers continue to collect published discussions of magnet reliability and component failures. In FY-95, several data sources were collected concerning reliability of components in magnet power systems. These operating experience data sources were discussed in ITER/US/95/TE/SA-31. ${ }^{5}$ In late FY-94, one researcher traveled to Fermi National Accelerator Laboratory (FNAL) to share data on component reliability. Unfortunately, the FNAL researchers do not collect failure rate data on the component level, only down-time or outage time on the system level. Therefore, the FNAL personnel did not have data to 
share for possible extrapolation to magnetic fusion components. The results of this trip to FNAL were reported in ITER/US/95/TE/SA31.

Other Analysis Tools. In assessing occupational and equipment exposures to magnetic fields in areas surrounding a tokamak, the fields due to the poloidal field and central solenoid coils are often important contributors. Unfortunately, the large size of the poloidal field and central solenoid coils makes the dipole approximation inadequate for calculating the field. The dipole approximation will give adequate results along the $\mathrm{z}$-axis and at points far from the coil, but it is not valid at other locations. Therefore, an elliptic integral must be solved to calculate magnetic fields at other locations, such as immediately outside the ITER cryostat.
This $\mathrm{EDF}^{2}$ and associated spreadsheet were written containing the derivation of an elliptic integral solution for an arbitrary set of coaxial current loops. The solution is valid in all regions surrounding the coils. Of course, the solution asymptotically approaches the dipole solution at locations far from the coil. The only approximation in the solution is that the coils are assumed to be filaments, i.e., the cross-section of the conductor is assumed to be zero. This approximation is reasonable since the ratio of coil thickness to the typical distances considered is small.

\section{Future Activities}

Our participation in the safety analysis of the ITER magnet set will be severely reduced due to funding limitations during FY-96. The analysis, which will be performed in collaboration with the Forschungszentrum Karlsruhe, (FZK, previously $\mathrm{KfK}$ ) will assist in the analysis of faults in the power supp lies and in the grounding system. 


\section{References}

1. J. Stephen Herring Trajectory of a Ferromagnetic Object in the Ex-Vessel Poloidal Field, ITER/US/95/TE/SA-30, September 29, 1995.

2. J. Stephen Herring, Elliptical Integral Solution for Coaxial Current Filaments, ITER/US/95/TE/SA-28, September 19, 1995.

3. L. C. Cadwallader, Magnet Operating Experience Review for Fusion Applications, EGG-FSP9977, November 1991.

4. Private communication, $\mathrm{K}$. Young, MRI Lead Technician, Eastern Idaho Regional Medical Center, October 31, 1995.

5. J. Stephen Herring and Lee C. Cadwallader, Final Report on the Magnet Safety Task for 1994 and 1995, ITER/US/TE/SA-31, October 2, 1995. 


\section{FUSION SAFETY COMPUTER CODE DEVELOPMENT}

\section{Researchers: K.E. Carlson, M.J. Gaeta, D.L. Hagrman, B.J. Merrill, D.A. Petti-INEL; S.C. Jardin-Princeton Plasma Physics Laboratory}

Fusion experiments, and eventually fusion power plants, will generate or contain radioactive material in the form of activation products and tritium. These machines will have a variety of energy sources that can mobilize these materials in several different forms during loss-of-vacuum-accidents (LOVAs), lossof-cooling-accidents (LOCAs), or plasma disruptions. These energy sources include: fusion neutron and particle heat, structure decay heat, plasma-stored thermal and magnetic energy, coolant pressurization, chemical reactions, and hydrogen production and possible combustion. The mobilized forms radioactive material can take are: (1) dust resulting from plasma-facing-component (PFC) erosion during normal operation which can contain tritium or activation products, (2) aerosols resulting from structure surface oxidation, (3) aerosols resulting from PFC erosion during plasma disruptions, (4) isotopic exchange of tritium from PFCs with spilt coolants, and (5) cooling system corrosion products. The extent to which these materials can be confined, and thereby the amount of radioactive material released to the environment reduced, will depend on the degree to which the integrity of confinement barriers can be maintained during LOVAs, LOCAs, and plasma disruptions.

The objective of this task is to obtain, modify, or develop safety computer codes capable of analyzing these events. Several codes are now being pursued. These codes are: ATHENA, CHEMCON, DSTAR, and MELCOR. The following paragraphs describe our progress during FY-95.

\section{Major Accomplishments}

ATHENA. Fusion reactors will require several interacting coolant systems to remove heat from the first wall, blanket, limiter or divertor, and cryogenic superconducting magnets. Different cooling fluids will be used in each of the systems. These separate systems will be interconnected by heat exchangers. To understand and analyze the interactions among these cooling systems, the Idaho National Engineering Laboratory (INEL) is developing a transient analysis code called ATHENA ${ }^{1}$ to simulate both routine and accident conditions.

ATHENA is a nonequilibrium model of the two-phase fluid conservation equations. The ATHENA code is based on the RELAP5/MOD3 code $^{2}$ and is being developed by modifying RELAP5 to include a range of fluids and new constitutive models. ATHENA also includes many generic component models from which general systems can be modeled, such as: pumps, valves, pipes, heat structures, electric heaters, jet pumps, turbines, separators, and control system components. In addition, special process models are included for effects such as form losses, flow at abrupt area changes, branches, choked flow, magnetohydrodynamic (MHD) effects, solute tracking and non-condensable gases.

This fiscal year, the ATHENA code was added to the ITER Integrated Safety Analysis System (ISAS) simulation code. This code is being developed by the ITER Safety Team to 
provide a self-consistent tool for analyzing the integrated response of ITER cooling systems and the reactor building during LOCAs by coupling thermal hydraulic codes, such as ATHENA, with aerosol transports codes. An ATHENA input model for the vacuum vessel cooling system was also developed as part of this task.

CHEMCON. During LOCA scenarios, steam may ingress into the plasma chamber from the first wall/shield cooling system, when the break of this system is within the vacuum vessel. Air may also ingress due to a failure of a vacuum vessel penetration. The CHEMCON code has been developed to study these conditions. The CHEMCON code contains a one-dimensional, cylindrical geometry, finite difference conduction model with specialized models that account for energy generation in the first wall armor due to chemical reactions with air or steam. In addition, it also allows multiple heat transfer modes and heating or cooling to be present in user-specified regions.

This year, two major modification efforts were conducted on the CHEMCON code. First, a pressurization/condensation model was developed and added to the CHEMCON code. $^{3}$ This model allowed the blowdown of a coolant volume into an initially low pressure plasma chamber. The pressurization resulting in the plasma chamber from this blowdown and the possible blowdown of the plasma chamber into a third volume representing the suppression pool were also modeled. The second modification performed was a multisegment model. 4 This model was designed to simulate different poloidal portions of the first wall/shield. The model consists of onedimensional, cylindrical region groups or segments that can be coupled at the innermost and outermost surfaces to the surfaces of other segments.

DSTAR. Tokamak plasma disruptions can produce severe structural damage and potentially mobilize tritium, activated dust, and structure activation products. For example, "hard" plasma disruptions rapidly release the plasma magnetic and thermal energy, creating significant protective tile erosion, and induced structural forces. In addition, high loop voltages occur that can generate high energy runaway electrons. If the generated runaway current is large, these electrons could cause significant first wall and blanket damage when lost from the plasma.

With these issues in mind, the focus of this task has been on developing and validating comprehensive models to ensure that proposed reactor designs can safely withstand off-normal plasma events. These models are being added to the Tokamak Simulation Code (TSC), ${ }^{5}$ a tokamak free-boundary plasma physics code under development at the Princeton Plasma Physics Laboratory (PPPL), with the resulting code being called DSTAR. ${ }^{6}$ In adopting this approach, we self-consistently deal with plasma disruptions by accounting for plasma motion, plasma/impurity transport, and induced structural eddy currents.

This year, a runaway electron model was added to the DSTAR code. These electrons are accelerated to high energies by the large toroidal electric field that develops during the current decay phase of a tokamak plasma disruption. Given the damage these electrons can cause if allowed to impact the first wall/blanket/shield structure, these electrons are a safety concern. This new model includes the runaway electron generation processes of 
Dreicer evaporation and secondary knock-ons. The orbits and energies of the runaway electrons are computed, as well as the vessel deposition distribution. To calibrate our model, we compared results from this model with those from a one-dimensional cylindrical test case and with experimental data from a disrupting TFTR plasma. The results of this comparison were presented in a poster at the American Physical Society Plasma (APS) Physics Meeting held in Louisville, KY during November 6-10, 1995.

MELCOR. The International Thermonuclear Engineering Reactor (ITER) will contain radioactive material in the form of activation products and tritium. ITER will have a variety of energy sources that can mobilize these materials during hypothetical accidents, such as a LOCA. MELCOR allows for a non-equilibrium treatment of both the liquid and vapor phases of water, and the transport of both phases along with aerosols between computational volumes of the system being modeled. ${ }^{7}$

Two major code development efforts were conducted on MELCOR this fiscal year. First, models for the oxidation of beryllium, carbon, and tungsten in steam environments were added. In addition, the capability of modeling the freezing of water and the condensation of air on structures that are at cryogenic temperatures was also added. ${ }^{8}$ Second, the equation of state for helium was added to MELCOR to allow modeling of LOCAs involving cryogenic components cooled by liquid helium. ${ }^{9}$

Three main modeling efforts were conducted this year in support of the ITER Early Safety and Environmental Characterization Study (ESECS) document. These models were developed to assess the consequences of LOCA into the heat transport system (HTS) equipment vault with a failure to shutdown the plasma burn in ITER. The consequences of interest were the time to first wall melt, and the amount of hydrogen that would be generated as a result of beryllium/steam reactions. Single coolant loop MELCOR models of the November Garching first wall/shield blanket (FW/SB) and divertor designs were developed and applied to this accident scenario.10 A two-loop model of the November Garching FW/SB design was also developed along with single and two-loop models of the March Garching FW/SB design. ${ }^{11}$ Finally, a sensitivity study was performed using the March Garching FW/SB model to determine the amount of hydrogen that would be generated by this accident scenario as a function of FW failure temperature. ${ }^{12}$

Figure 3 shows a schematic of the singleloop MELCOR model developed during these efforts. All major loop component volumes were modeled. The ex-vessel LOCA occurs in the cold plenum of the FW/SB cooling system. Cooled in-vessel surfaces were also modeled to include condensation of steam within the plasma chamber.

Figure 4 shows the temperatures at various points in the ITER March FW/SB design during a large ex-vessel FW LOCA. Temperatures are shown at the plasma facing beryllium surface, the stainless steel back of the first wall, the front and back of the shield, the back of the manifold and the back of the backplate of the FW/SB structure. 


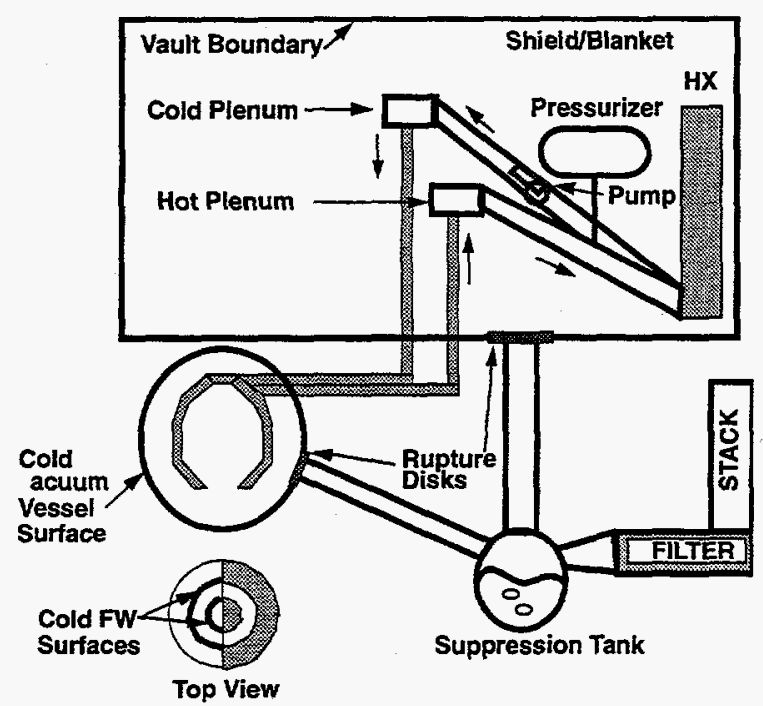

Figure 3. MELCOR single-loop model schematic.

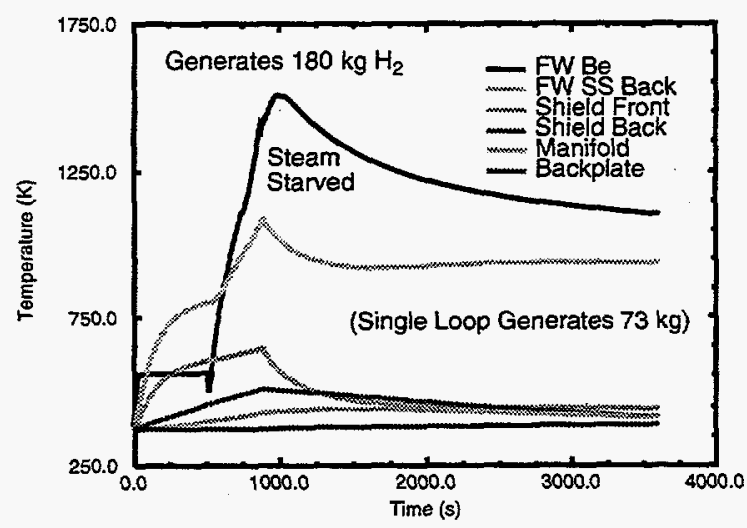

Figure 4. Transient temperatures in ITER FW/SB component and hydrogen produced for large ex-vessel LOCA

Figure 5 summarizes the results from the sensitivity study. Shown in this figure is the amount of hydrogen produced as a function of assumed FW failure temperature. Also indicated in Figure 5 is the time it takes for the FW to reach the assumed failure temperature. Assuming a smaller FW breach size (e.g., 0.11 $\mathrm{m}^{2}$ versus $0.664 \mathrm{~m}^{2}$ ) had very little effect on the results of Figure 5 . However, assuming the simultaneous failure of an auxiliary volume increased the hydrogen produced by $50 \%$, while assuming only the failure of this auxiliary volume doubled the amount of hydrogen produced.

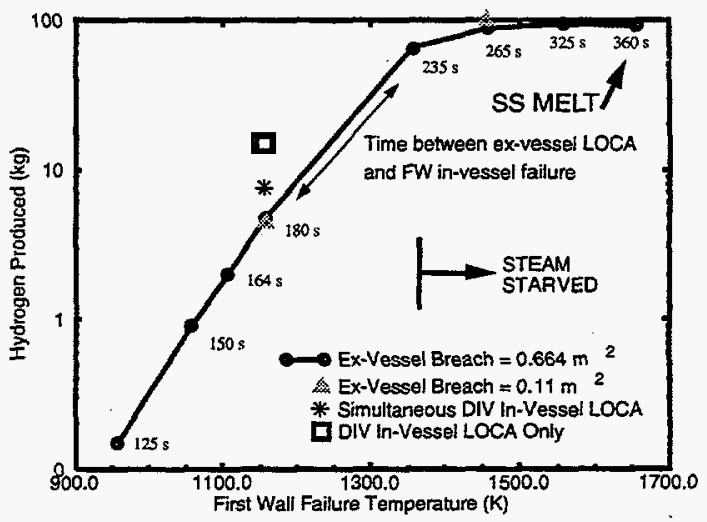

Figure 5. Sensitivity of hydrogen production to assumed first-wall failure temperature.

\section{Future Activities}

During the upcoming fiscal year, modifications to MELCOR will be made to better model the behavior of aerosols present during hypothetical thermal-hydraulic accidents such as LOCAs and LOFAs. 


\section{References}

1. K. E. Carlson, P. A. Roth and V. H. Ransom, ATHENA Code Manual, Volume I and 2, EGG-RTH-7397, September 1986.

2. C. M. Allison, et al., RELAP5/MOD3 Code Manual, Volumes 1, 2, 3, and 4, NUREG/CR5535, EGG-2596, June 1990.

3. M. J. Gaeta and B. J. Merrill, CHEMCON User's Manual Version 2.2, INEL-95/0147, April 1995.

4. M. J. Gaeta and B. J. Merrill, CHEMCON User's Manual Version 3.1, INEL-95/0147, September 1995.

5. S. C. Jardin, N. Pomphrey, and J. Delucia, "Dynamic Modeling of Transport and Positional Control of Tokamaks," Journal of Computational Physics, 66, 1986, p. 481.

6. B. J. Merrill, S. C. Jardin, "DSTAR: A Comprehensive Tokamak Resistive Disruption Model For Vacuum Vessel Components," Fusion Engineering and Design, 5, 1987, pp. 235-249.

7. R. M. Summers, R. K. Cole, Jr., E. A. Boucheron, M. K. Carmel, S. E. Dingman, J. E. Kelly, MELCOR 1.8.0: A Computer Code for Nuclear Reactor Severe Accident Source Term and Risk Assessment Analyses, NUREG/CR-5531 and SAND90-0364, January 1991.

8. D. L. Hagrman and B. J. Merrill, Initial Modifications to the MELCOR Code, ITER/US/95/TE/SA-18, June 1995.

9. D. L. Hagrman and B. J. Merrill, Additional of Helium Properties to the MELCOR Code, ITER/US/95/TE/SA-24, September 1995.

10. B. J. Merrill and M. J. Gaeta, MELCOR Ex-Vessel LOCA Analyses in Support of ESECS, ITER/US/95/TE/SA-03, February 1995.

11. M. J. Gaeta and B. J. Merrill, Additional MELCOR Ex-Vessel LOCA Analyses in Support of ESECS, ITER/US/95/TE/SA-14, May 1995.

12. M. J. Gaeta and B. J. Merrill, MELCOR ITER LOCA Sensitivity Calculations in Support of ESECS, ITER/US/95/TE/SA-20, August 1995. 


\section{RISK ASSESSMENT}

\section{Researchers: L. C. Cadwallader, M. L. Abbott, and A. S. Rood- INEL; T. D. Marshall-Rensselaer Polytechnic Institute}

The Fusion Safety Program (FSP) leads the U.S. effort in using risk assessment in fusion experiment design to provide safety for the public and the environment. Risk assessment is also a part of the design effort for the International Thermonuclear Experimental Reactor (ITER). Two important features of fusion risk assessment are system analysis and radiological dose assessment. Progress in these facets of fusion risk assessment work in FY-95 is discussed below.

\section{Major Accomplishments}

System Analysis. INEL researchers supported work on the ITER Early Safety and Environmental Characterization Study (ESECS). Research focused on a failure modes and effects analysis of the vacuum vessel, the failure mechanisms and failure rates of safety components for ITER, selected initiating events, and other issues of interest. ${ }^{1-3}$ The initial draft of ESECS was published by the ITER Joint Central Team (JCT) in mid1995.

Later in the fiscal year, attention returned to assembling a component failure-rate data bank for supporting probabilistic safety analyses, mainly the upcoming ITER Non Site-specific Safety Report (NSSR). A taxonomy of component types listed by major plant systems was developed and then augmented with the expected failure modes for these components. 4,5 Work continues to provide component failure rate information by failure mode and to develop component repair rates and downtimes. These data will be used with the recently upgraded Software Toolkit for Advanced Reliability and Safety analysis (STARS), ${ }^{6}$ the chosen ITER risk assessment computer code. The data will reside in electronic spreadsheet form. This data compilation task compliments the International Energy Agency's cooperative task on development of a failure rate data base for fusion experiments.

Another area of risk and safety assessment is estimation of time frames that safety actions or equipment actuations must be performed. Under the auspices of Sandia National Laboratory, researchers are examining the theoretical and experimental times to divertor tubing burnout in loss of flow accident (LOFA) situations. A LOFA is conceivable over the lifetime of ITER. The mechanisms that lead to LOFAs must be studied because of the potentially severe consequences of tube burnout. These studies help support the design efforts under way to mitigate LOFA events. Progress in the theoretical and experimental divertor LOFA studies were reported in several papers. ${ }^{7-9}$

\section{Dose Consequence Computer Codes.}

The work for this year was a continuation of work from FY-94. The scalable radiological dose calculations on Excel spreadsheets for accident releases 10 were amended with new $\mathrm{Chi} / \mathrm{Q}$ values for locations near the vent stack. ${ }^{11}$ The spreadsheet was also modified to perform additional calculations for cases involving rainfall during the radionuclide re- 
lease. The spreadsheets sent to the ITER JCT were updated accordingly. These tasks completed the interim work on the spreadsheet tools for routine and accident releases of radionuclides. These spreadsheets will be used to support the NSSR consequence studies.

\section{Future Activities}

We shall continue to support the ITER JCT and the U.S. Home Team with risk analysis, including event tree analysis, component failure rate and repair rate assessment and compilation, and radiological dose assessments as they are needed for NSSR and other safety requirements. The LOFA task at Sandia National Laboratory will be nearing completion in FY-96. 


\section{References}

1. L. C. Cadwallader, Vacuum Vessel FMEA and Suggested Penetration Failure Rates for the ITER, U.S. Home Team Engineering Design File ITER/US/94/TE/SA-23, December 12, 1994.

2. L. C. Cadwallader, Preliminary Failure Rates for Selected ITER Safety Systems, U.S. Home Team Engineering Design File ITER/US/94/TE/SA-24, December 16, 1994.

3. L. C. Cadwallader, Preliminary Estimates of Frequencies for Reference Postulated Initiating Events, U.S. Home Team Engineering Design File ITER/US/94/TE/SA-25, December 16, 1994.

4. L. C. Cadwallader, Preliminary Component Taxonomy for the International Thermonuclear Experimental Reactor Engineering Design Activity, U.S. Home Team Engineering Design File ITER/US/95/TE/SA-7, April 28, 1995.

5. L. C. Cadwallader, Preliminary Taxonomy of Components and Failure Modes for the ITER EDA, U.S. Home Team Engineering Design File ITER/US/95/TE/SA-21, August 28, 1995.

6. J.-P. Nordvik et al., "Computer-Based System Modelling for Reliability and Safety Analysis," Proceedings of the Topical Meeting on Computer-Based Human Support Systems: Technology, Methods, and Future, Philadelphia, PA, June 25-29, 1995, pp. 211-217.

7. T. D. Marshall et al., "An Experimental Investigation of the Post-CHF Enhancement Factor for a Typical ITER Divertor Plate," presented at NURETH-7, the 7th International Meeting on Nuclear Reactor Thermal-Hydraulics, Saratoga Springs, New York, Sept. 11 - 15, 1995.

8. T. D. Marshall et al., "An Experimental Investigation of the Post-CHF Enhancement Factor for a Prototypical ITER Divertor Plate with Water Coolant," presented at the 16th Symposium on Fusion Engineering, Urbana, Illinois, October 1-5, 1995.

9. T. D. Marshall et al., "Time-to-Burnout Data for a Prototypical ITER Divertor Tube During a Simulated Loss of Flow Accident," presented at the 16th Symposium on Fusion Engineering, Urbana, Illinois, October 1-5, 1995.

10. M. L. Abbott et al., Dose Calculations for Accidental Airborne Releases of ITER Activation Products, EGG-EEL-10994, December 1993.

11. M. L. Abbott, Revision to Chi/Q Data Files in the U.S. Computerized Dose Worksheet (Scoping Tool), U.S. Home Team Engineering Design File ITER/US/95/TE/SA-1, February 2, 1995. 


\section{COMMERCIAL REACTOR SYSTEM DESIGN STUDIES}

\section{Researchers: J. S. Herring, K. A. McCarthy and T J. Dolan-INEL}

During the last 7 years the Fusion Safety Program has participated in the ARIES, PULSAR, and STARLITE design studies. The purpose of these studies has been to produce a set of self-consistent commercial designs. In the course of integrating the designs, we have identified the plasma conditions, materials, and reactor configurations necessary to produce a commercially acceptable fusion reactor. Other participants in these studies have included the University of California at Los Angeles, San Diego and Berkeley, the Massachusetts Institute of Technology, the Los Alamos, Argonne, and Oak Ridge National Laboratories, General Atomics, and other industrial and utilities representatives.

\section{Major Accomplishments}

During FY-95, we performed a Hazards Assessment for the STARLITE Demonstration fusion reactor design. This Hazards Assessment was based on the parameters of the ARIES-IV design. We also contributed to the assessment of the feasibility of vanadium as a structural material for fusion reactors.

Hazards assessment for STARLITE The objective of a hazards assessment is to determine the radioactive releases to the surrounding population from credible accidents under realistic weather conditions. We modeled the release of the radioactive inventory in the ARIES IV design under the conditions given for a helium coolant line break. Those conditions are:
1. The release is initiated by an offset rupture of a $1.1-\mathrm{m}$ (inner diameter) coolant line, somewhere between the vessel and the heat exchanger.

2. Circulation of helium coolant stops and heatup ensues.

3. Immediate release of tritium and activation product inventory in the coolant takes place.

4. There is a slow release of activation products and tritium from the structure and breeder, as determined by the temperature rise.

The primary concern will be the release of three tritium inventories: (1) the tritium entrained in the primary helium coolant stream (about 1-5 grams), (2) the tritium in the purge stream (5-10 grams), and (3) the tritium inventory contained within the beryllium multiplier (400 grams according to neutronics calculations, tritium retention experiments and temperature distribution studies.)

Tritium release via gas streams. We assumed that the tritium released via the coolant and purge streams is immediately oxidized to HTO. The blowdown of the $1.1-\mathrm{m}$ diameter, 10 to $18-\mathrm{MPa}$, helium coolant line will last about $10 \mathrm{~s}$.

Tritium release from beryllium. Tritium is produced in the beryllium multiplier at about $1 \%$ of the rate of tritium production in the lithium breeder. Thus, between 3 and 4 
grams are produced per day of full power operation. Tritium is retained in beryllium up to a temperature of $900 \mathrm{~K}$, at which temperature it is quickly released. During operation, about a third of the blanket will operate below 900 $\mathrm{K}$ and thus accumulate tritium. We assume that the blanket is uniformly heated every year to drive off the accumulated tritium. We further assume that the transient occurs just before one of these annual heating sessions.

Thus, the accumulated inventory in the beryllium operating below $900 \mathrm{~K}$ is about 400 grams. We could lower the tritium inventory through more frequent multiplier heating, e.g. semiannually or quarterly.

According to the heating rates shown in Table 1, the temperature of the SiC rises $75 \mathrm{~K}$ during the four hours following the rupture of the cooling line. Thus it is plausible that 400 grams of tritium would be released over a four to ten-hour period.

Table 1. Tritium releases from ARIES IV.

\begin{tabular}{lrl}
\hline $\begin{array}{l}\text { Helium coolant stream } \\
\text { inventory }\end{array}$ & 3 & $\mathrm{~g}$ \\
& 29,064 & $\mathrm{Ci}$ \\
Blowdown time & 5 & $\mathrm{~s}$ \\
\hline Purge stream inventory & 6 & $\mathrm{~g}$ \\
& 58,128 & $\mathrm{Ci}$ \\
Blowdown time & 60 & $\mathrm{~s}$ \\
\hline Beryllium inventory & 400 & $\mathrm{~g}$ \\
& $3,875,200$ & $\mathrm{Ci}$ \\
Release time & $8 \mathrm{hr}$ \\
& 28,200 & $\mathrm{~s}$ \\
\hline
\end{tabular}

Thus, the average release rates over different time intervals would be:

$\begin{array}{lccc}\text { time (s) } & 0-5 & 5-60 & 60-28,800 \\ \mathrm{Ci} / \mathrm{s} & 6,800 & 970 & 135\end{array}$

Assessment of Vanadium for use in DEMO. Vanadium alloys have the potential for superior safety and environmental characteristics, when compared with other near-term structural materials. A safety evaluation of any structural material must include the impact of routine emissions, dose rates in working areas, decay heat, potential off-site doses from hypothetical accidents, and the management of end-of-service material. The two safety aspects of primary importance in assessing a material for use in the DEMO reactor are the consequences of accidents and the options for waste management.

\section{Consequences of Accidental Releases}

Potential doses from an accidental release of activated material depend on the radioactive inventory, the volatility of the compounds containing the radionuclides, and available means of transport for the radionuclides to the facility boundary. The isotopes governing early off-site doses are ${ }^{48} \mathrm{Sc},{ }^{42} \mathrm{Ar},{ }^{24} \mathrm{Na},{ }^{46} \mathrm{Sc}$, ${ }^{45} \mathrm{Ca}$ and ${ }^{51} \mathrm{Cr}$. The potential for mobilization of specific elements from fusion-relevant materials in high-temperature excursions under oxidizing conditions has been investigated in experiments at the INEL. ${ }^{1}$ In the vanadium alloy volatility tests, vanadium alloys were doped with scandium, calcium and manganese to simulate the activation products. Based on the release rates observed in these experiments, elemental mobilization fractions were calculated for the alloys $\mathrm{V}-15 \mathrm{Cr}-5 \mathrm{Ti}$ and $\mathrm{V}$ 3Ti-1Si corresponding to a material thickness of $5 \mathrm{~mm}$ and one hour at elevated temperature.

The early doses to an individual at $2 \mathrm{~km}$ for both V-15Cr-5Ti and V-3Ti-1Si were above a factor 30 below those for $316 \mathrm{~L}$ stainless steel for a range of first wall temperatures from $900-1500 \mathrm{~K}$. With the $\mathrm{V}-15 \mathrm{Cr}-5 \mathrm{Ti}$ alloy, ${ }^{42} \mathrm{Ar}$ dominates the dose at the lower 
temperatures while ${ }^{48} \mathrm{Sc}$ dominates at higher temperatures. It is assumed that all the argon is released over the 7-day duration of the accident. Other isotopes contributing more than $5 \%$ to the early dose are ${ }^{46} \mathrm{Sc},{ }^{45} \mathrm{Ca}$, and ${ }^{51} \mathrm{Cr}$.

With the V-3Ti-1Si alloy, off-site doses are governed by ${ }^{24} \mathrm{Na}$ at lower temperatures and $48 \mathrm{Sc}$ at higher temperatures. A conservative value of 0.3 , based on the properties of sodium at typical accident temperatures, was used in the absence of experimental data on the mobilization fraction for sodium. Additional isotopes contributing more that $5 \%$ to the early dose are ${ }^{46} \mathrm{Sc},{ }^{45} \mathrm{Ca}$ and ${ }^{42} \mathrm{Ar}$.

Options for Waste Management. The waste management options for vanadium components are either recycling or direct disposal. The recycling option involves remelting the alloy to remove radioactive species and reclaiming the metal for use in new components, with either shallow land burial or deep geological burial of the separated nuclides.

Over the period relevant to waste disposal, the radioactive inventory of the vanadium alloys is dominated by the argon isotopes ${ }^{39} \operatorname{Ar}\left(\mathrm{t}_{1 / 2}=269 \mathrm{y}\right)$ and ${ }^{42} \mathrm{Ar}\left(\mathrm{t}_{1 / 2}=33\right.$ $y)$, generated almost entirely from the titanium. The argon inventories at shutdown for the alloy V-15Cr-5Ti exposed in first wall and blanket positions are given in Table 2. Inventories for $\mathrm{V}-3 \mathrm{Ti}-1 \mathrm{Si}$ are approximately $60 \%$ of these.

Table 2. Argon inventories at shutdown.

\begin{tabular}{lllll}
\hline & \multicolumn{2}{c}{${ }^{39} \mathrm{Ar}$} & \multicolumn{2}{c}{${ }^{42} \mathrm{Ar}$} \\
\cline { 2 - 5 } First wall & $\mathrm{g} / \mathrm{kg}$ & $\mathrm{Bq} / \mathrm{kg}$ & $\mathrm{g} / \mathrm{kg}$ & $\mathrm{Bq} / \mathrm{kg}$ \\
\cline { 2 - 5 } Blanket & $4.9 \mathrm{e}-7$ & $6.2 \mathrm{e} 5$ & $2.0 \mathrm{e}-6$ & $1.9 \mathrm{e} 7$ \\
& $2.2 \mathrm{e}-9$ & $2.7 \mathrm{e} 3$ & $1.1 \mathrm{e}-8$ & $1.1 \mathrm{e} 5$ \\
\hline
\end{tabular}

Two possible mechanisms can be envisioned for release of the argon after disposal: first, the argon may diffuse out of the metal, and second, it could be released during corrosion. The first mechanism is unlikely to dominate since, if the argon has remained immobile in the alloy throughout service, when the temperature of the material may line in the region of $900 \mathrm{~K}$, it is improbable that the gas will escape in a repository where the temperature is not likely to exceed $350 \mathrm{~K}$.

In assessing the second mechanism, relevant corrosion information for the alloys is needed. Since that information is not available, the behavior of pure vanadium has been taken as a guide. Although vanadium should theoretically corrode under reducing, high $\mathrm{pH}$ conditions, it is found in practice that its corrosion behavior is similar to that of a noble metal. Thus the direct disposal of vanadium alloy is tantamount to the employment of large volumes of expensive, essentially inactive metal as a packaging medium for extremely low concentrations of activation products.

Recycling. The relative volatility of the main activation products suggests a recycling process based on high-vacuum remelting or refining, with immobilization of the liberated argon isotopes in a stable metal matrix of low volume for geological disposal. With adequate initial purity control, several usage cycles should be possible, thus greatly reducing the consumption of vanadium alloy and the volume of waste requiring geological isolation. Moreover, the use of recycled material is found not to affect the low offsite accident dose calculated for these vanadium alloys. 
Interaction with the development of the Fusion Safety Standard. Through the Fusion Systems Studies Utilities Advisory Committee, we have received the emphatic guidance that any viable commercial fusion power plant must not require an evacuation plan for the general public. Avoiding any need for a public evacuation plan has been a goal of the ARIES, PULSAR and STARLITE designs from their inception. Based on the guidance from the Utilities Advisory Committee, the accidental public exposure limits in the Fusion Safety Standard were written such that no public evacuation would be required.

\section{Future Activities}

The systems studies task will place special emphasis this year on the development of credible and mechanistic accident sequences. Previous analyses have been based primarily on the inventories of radioactivity and energy, without determining how that inventory might be released. Furthermore, the previous analyses have given very little credit to aerosol deposition and hindered transport of radionuclides through the reactor building. We generally feel that the LSA analyses are placing fusion at a comparative disadvantage with respect to other energy sources and that, in future design studies, we should use more mechanistic and credible accident sequences consistent with current practice in competing technologies. 


\section{Reference}

1. Butterworth, G. J., K. A. McCarthy, G. R. Smolik and C.B.A. Forty, "Safety and Environmental Aspects of Vanadium Alloys," Journal of Nuclear Materials, 212-215, 1994, pp. 667672. 


\title{
TOKAMAK FUSION TEST REACTOR AND TOKAMAK PHYSICS EXPERIMENT SAFETY SUPPORT
}

\author{
Researchers: C. G. Motloch and R. F. Bonney-INEL; \\ J. C. Commander-Consultant; M. A. McKenzie-Carter-SAIC; \\ L. S. Masson-Scientech; and J. D. Levine-PPPL
}

The INEL FSP continued providing safety support to the Princeton Plasma Physics Laboratory (PPPL). This included completion of the Preliminary Safety Analysis Report (PSAR) for the proposed Tokamak Physics Experiment (TPX).

The Tokamak Fusion Test Reactor (TFTR) was in its last phase of operations and was scheduled for shutdown followed by removal of most of its major hardware. Subsequently, the TFTR facility was planned to be reused to house the TPX. The purpose of TPX was to develop the scientific basis for a compact and continuously operating tokamak fusion reactor. ${ }^{1}$ The TPX design was based on planned deuterium-deuterium (DD) operations, but it did not preclude the future deuterium-tritium (DT) operations. The DOE has not funded the TPX in FY-96.

\section{Major Accomplishments}

Several safety documentation tasks were completed during this period. The TPX Preliminary Safety Analysis Report (PSAR) ${ }^{2}$ (DOE TPX Project Milestone 2-6) was approved by Cherri J. Langenfield, Manager of the DOE Chicago Operations Office, and subsequently distributed to all TPX managers.
The TPX PSAR incorporates the graded approach philosophy per DOE-STD-3009$94^{3}$ for nonreactor nuclear facilities, but will follow the DOE Order $5480.23^{4}$ 20-chapter format for nuclear safety analysis reports. For TPX to maintain a less-than-Category-3 Hazard classification per DOE-STD-1027-92 tritium inventory will be kept below $1,000 \mathrm{Ci}$ for DD operations. TPX will have no safetyclass systems, structures, or components (SSCs), but may have safety-significant SSCs. The criteria for safety-significant SSCs per DOE-STD-3009-94 are shown in Figure 6, and criteria for defense-in-depth and worker safety are in Table 3.

The generic list of hazards given subsequently was developed for the TPX hazards analysis. The list was screened to eliminate incredible and standard industrial hazards. (Credible is defined as having a frequency of occurrence equal to or greater than 1 $\times 10^{-6}$ per year.) The hazards remaining after the screening are chemical exposure, explosion, fire, and ionizing radiation exposure. A risk assessment of these hazards was performed, and the results are summarized in Table 4, which shows that the risks from fire are low for abnormal conditions and accident conditions, and the risk from ionizing radiation is low for normal conditions. All other risks were determined to be negligible. 
Does the SSC have a preventive or mitigative function that is a major contributor to defense-in-depth (i.e., prevention of uncontrolled material release) as determined from hazard analysis?

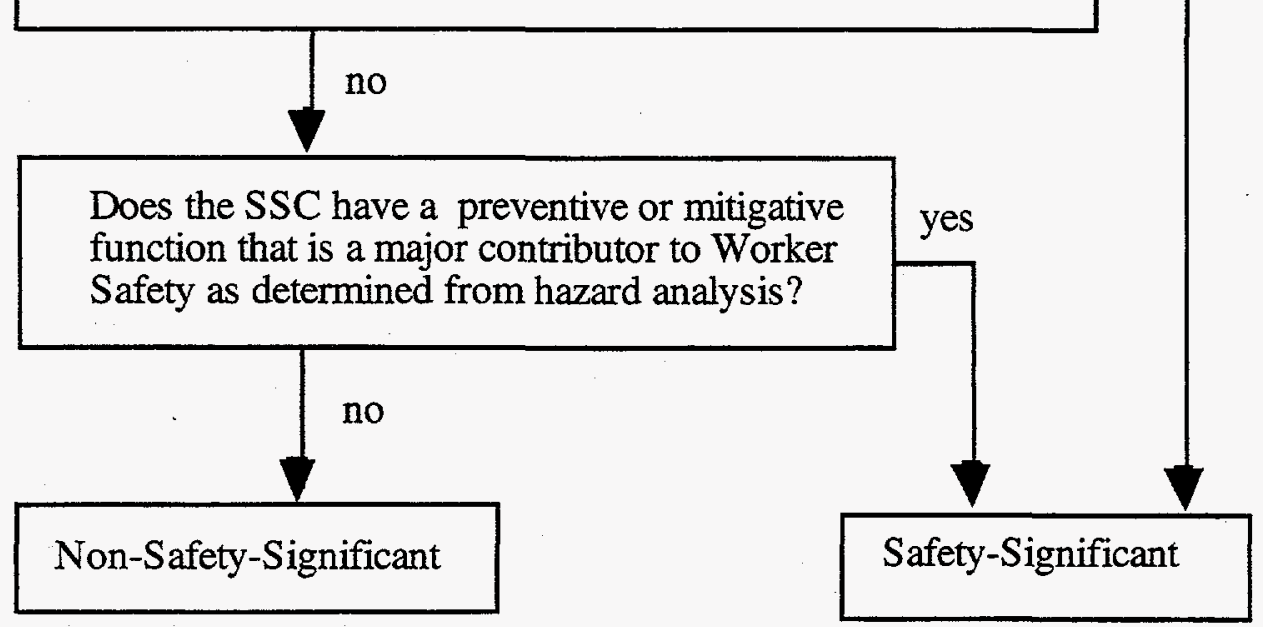

Figure 6. Criteria for safety-significant SSCs per DOE STD-3009-94.

Table.3 Defense-in-depth and worker safety SSCs.

Defense-in-depth SSCs

Includes

Excludes

- Administrative features

- Safety management

programs
Worker safety SSCs

- Equipment to prevent or mitigate acute fatalities or serious injuries

- Standard industrial hazards

- Latent effects

- Procedures

Table 4. Results of TPX risk assessment.

Risk level (probability $\mathrm{x}$ consequence)

\begin{tabular}{lccc} 
& Normal condition & Abnormal condition & Accident condition \\
\hline Chemical & negligible & negligible & negligible \\
Fire & negligible & low & low \\
Explosion & negligible & negligible & negligible \\
Ionizing radiation & low & negligible & negligible \\
\hline
\end{tabular}


The generic hazards are as follows:

- Aircraft impact

- Chemical exposure

- Compressed gases

- Construction hazards

- Cryogenic hazards

- Electrical hazards

- Explosion

- Fire

- Flammable gases, liquids, and dusts

- Flooding

- High-intensity magnetic fields

- High noise levels

- High winds

- Inadequate illumination

- Inadequate ventilation

- Ionizing radiation exposure

- Low oxygen atmosphere

- Material handling dangers

- Mechanical and moving equipment dangers
- Nonionizing radiation sources

- Seismic events

- Temperature extremes

- Volcanism

- Working at heights.

A draft of the TPX PSAR Design Features was presented at the TPX Engineering Meeting in May for review and comment. The Quality Assurance files for the TPX Environmental Assessment (DOE-0813) and the Quality Assurance files for the TPX PSAR were completed and transmitted to the TPX Project. The TPX Safety Support was completed on schedule and within budget.

\section{Future Activities}

DOE has not funded TPX in FY-96. Therefore, all support of the safety activities at PPPL have been terminated. 


\section{References}

1. Princeton Plasma Physics Laboratory, TPX Conceptual Design Overview, TPX Conceptual Design Review, March 29 - April 1, 1993, 91-930323PPPL/W. Reiersen-01.

2. C. G. Motloch et al., Preliminary Safety Analysis Report for the Tokamak Physics Experiment, INEL-95/0199, April 1995.

3. Preparation Guide for U.S. Department of Energy Nonreactor Nuclear Facility Safety Analysis Reports, DOE-STD-3009-94, July 1994.

4. DOE 5480.23, Nuclear Safety Analysis Reports, April 1992.

5. Hazard Categorization and Accident Analysis Techniques for Compliance with DOE Order 5480.23, Nuclear Safety Analysis Reports, DOE-STD-1027-92, December 1992.

6. C. G. Motloch and J. D. Levine, "WBS 92 Project Safety Documentation: TPX PSAR Design Features \& System Requirements," TPX Engineering Meeting, May 17, 1995, Princeton Plasma Physics Laboratory, Pinceton, NJ. 


\section{FUSION SAFETY STANDARD DEVELOPMENT}

\section{Researchers: G. R. Longhurst, G. A. Dinneen, J. S. Herring, D. A. Petti-INEL; D. J. Baker-WSRC, J. DeLooper-PPPL; M. J. Gouge-ORNL}

In anticipation of building future fusion devices in the U.S., there is a need for fusion safety documentation that will serve as the basis for licensing and regulation. This year, two DOE Standards were drafted to provide that basis. DOE-STD-6002-95 Safety of Magnetic Fusion Facilities - Requirements, and DOE-STD-6003-95 Safety of Magnetic Fusion Facilities - Guidance, were drafted and submitted to the Office of Fusion Energy for review and acceptance as fully coordinated DOE Standards. Though drafted in the form of a Standard, the Requirements doument (DOESTD-6002-95) was written in such a way that it can be upgraded to an Order or higher-level directive, should that become useful. The documents were prepared with the INEL in the leadership role. Support was provided by Oak Ridge National Laboratory, Westinghouse Savannah River Company, and Princeton Plasma Physics Laboratory.

Guidance in preparing the documents comes from the Fusion Safety Steering Committee consisting of three tiers of participants. The first group consists of the regular participants from the writers' institutions and a few others such as the Massachusetts Institute of Technology, Argonne National Laboratory, General Atomics, Ebasco, and Lawrence Livermore National Laboratory. The second tier consists of Ex-Officio Members who are all from various offices of DOE, mostly from Headquarters but also from the operations offices overseeing the writers' institutions. The final tier consists of reviewers coming from stakeholder institutions, including utilities.

\section{Major Accomplishments}

The major activity this year has been to assemble into concise form the material that was developed in FY-94 relating to requirements and guidance for implementting those requirements. The decision of the Fusion Safety Steering Committee was that the most suitable format would be as Technical Standards. The requirements cited in DOESTD-6002-95 are for the most part derived from the Code of Federal Regulations, but an additional requirement was added that even in the event of a severe accident, the radiological threat to the public must be low enough that no off-site evacuation plan will be needed. This added requirement has generated a substantial controversy. In the hierarchy of the DOE Directives Management System, it is not technically appropriate for requirements to appear in a Standard. They should appear in Orders or higher-level documents. It is important to note that the reqirement listed in the Standard is only a requirement for compliance with this Standard. If by incorporation in a contract, compliance with the Standard becomes mandatory for a contractor, then the requirements in the Standard are binding for the contractor.

The requirements in DOE-STD-6002-95 are high-level, general requirements and principles that leave considerable flexibility on the 
part of the owner of a fusion facility in determining how they will respond to those requirements. The companion document, DOESTD-6003-95, contains guidance on how to meet those requirements. Much more extensive and voluminous than DOE-STD-6002-95, it contains information and advice on how to meet the requirements as outlined in current DOE Orders, other Standards, and related documents.

In addition to these two Standards, a Preamble was written that provides an explanation and rationale for why the Standards were written as they were. It addresses major philosophical points that we tried to capture in writing the Standards. That Preamable will become an appendix to the Requirements Standard in its final configuration.

All three douments, the Preamble, the Requirements Standard, and the Guidance, were distributed, first to the U.S. fusion community, who will be most influenced by their content, and then to the DOE Standards Managers for review and acceptance. Distribution to the Standards Managers took place on September 18, 1995. Early in FY-96, the writers of the Fusion Safety Standards will prepare and coordinate responses to comments returned from that review. Assuming that is successful, the Standards will be issued and implemented. 


\section{APPENDIX A}

Abstracts or Summaries of Fusion Safety Program Publications 


\section{ITER DESIGN AND REGULATORY SUPPORT}

\section{ITER Principal Safety Functions: Radiological Confinement, Heat Removal, and Shutdown}

S. J. Piet, H.-W. Bartels, C. W. Gordon, A E. Poucet, and L. N. Topilski, 16th Symposium on Fusion Engineering, Urbana, IL, September 30-October 4, 1995.

The ITER safety team, including the Joint Central Team (JCT) and Home Teams, has considered the hazards associated with the design. The nature of these hazards suggest general safety approaches and criteria. Considering the challenges of the ITER experimental mission, we identify principal safety functions and a basic safety design strategy to meet project safety and environmental criteria.

\section{Key Results in ITER Safety Analysis} H.-W. Bartels, C. W. Gordon, D. Holland, S.J. Piet, A. E. Poucet, and L. N. Topilski, 16th Symposium on Fusion Engineering, Urbana, IL, September 30-October 4, 1995.

A set of ITER reference accident sequences is analyzed to determine if the ITER design has sufficient provisions to withstand these sequences without violating project safety and environmental criteria. These reference sequences have been selected as a result of a systematic sequence identification and screening process. A large family of accidents is grouped around the ITER cooling systems. Failures in the magnet system and tritium plant are investigated to demonstrate the adequacy of confinement.

\author{
An Overview of Safety and \\ Environmental Considerations in the \\ Selection of Materials for Fusion \\ Facilities \\ D. A. Petti, K.A. McCarthy, W. Gulden, S. \\ J. Piet, Y. Seki, and B. Kolbasov, Seventh \\ International Conference on Fusion \\ Reactor Materials, Obninsk, Russia, \\ September 25-29, 1995.
}

Safety and environmental considerations can play a large role in the selection of fusion materials. In this paper, we review the attributes of different structural, plasma facing, and breeding materials from a safety perspec-tive and discuss some generic waste management issues as they relate to fusion materials in general.

Specific safety concerns exist for each material that must be dealt with in fusion facility design. Low activation materials offer inherent safety benefits compared with conventional materials, but more work is needed before these materials have the requisite certified databases. In the interim, the International Thermonuclear Experimental Reactor (ITER) has selected more conventional materials and is showing that the safety concerns with these materials can be addressed by proper attention to design.

In the area of waste management, disposal criteria differ by country. However, the criteria are all very strict making disposal of fusion components difficult. As a result, recycling has gained increasing attention. 


\section{BERYLLIUM SAFETY}

\author{
Proceedings, 2nd IEA International \\ Workshop On Beryllium Technology \\ For Fusion, September 6-8, 1995, \\ Jackson Lake Lodge, Wyoming \\ G. R. Longhurst, CONF-9509218, \\ September 1995.
}

The 2nd IEA International Workshop on Beryllium Technology for Fusion was held September 6-8, 1995 at Jackson Lake Lodge, Wyoming. Forty-four participants took part in the workshop representing Europe, Japan, the Russian Federation, and the United States including representatives from both government laboratories and private industry. Cochairs of the workshop were G. R. Longhurst of the Idaho National Engineering Laboratory (INEL) and M. Dalle Donne of Forschungszentrum Karlsruhe (FzK), Germany. This is the second workshop in this areaq conducted under the auspices of the International Energy Agency (IEA). The first was at Karlsruhe, Germany in October of 1993. Prior to IEA sponsorship, similar workshops were held at the INEL in 1988 and at Clearwater Beach, Florida in 1991.

The workshop was divided into six technical sessions and a "town meeting" panel discussion. Technical sessions addressed the general topics of: (a) Thermomechanical Properties, (b) Manufacturing Technologies, (c) Radiation Effects, (d) Plasma/Tritium Interactions, (e) Safety, Applications, and Design, and (f) Joining and Testing.

This volume contains the majority of the papers presented at the workshop. In some instances, the authors of the papers could not be present at the workshop, and the papers were given by others, sometimes in summary form and in some instances combined with others. The full papers are included here in the sequence in which they would have been given. In other instances, presentations were made, but no papers were submitted for publication. Those papers do not appear here. 


\section{TRITIUM SAFETY}

Tritium And Helium Release From Irradiated Beryllium

R. A. Anderl, J. D. Baker, G. L. Bourne, and R. J. Pawelko, Fusion Technology, 28, October 1995, pp. 1114-1119.

Tritium and helium release behavior have been measured for $\mathrm{Be}$ specimens irradiated at $75^{\circ} \mathrm{C}$ in the Advanced Test Reactor (ATR) to a fast neutron fluence of $5 \times 10^{22} \mathrm{n} / \mathrm{cm}^{2}$. Stepped-isothermal anneal experiments were conducted from room temperature to above the melting point of $\mathrm{Be}$, with the temperature steps varied from one experiment to the other. In-line ion chambers and quadrupole mass spectrometers were used to measure the gases released to an Ar process gas stream flowing across a heated specimen. Gases released from the specimens included $\mathrm{H}_{2},{ }^{3} \mathrm{He},{ }^{4} \mathrm{He}$, and tritium as HT and $T_{2}$. Release of the hydrogenic and tritium gases were observed to be concurrent with the release of helium, providing direct evidence of these gases in microscopic helium bubbles in the irradiated $\mathrm{Be}$. Tritium and helium release kinetics were dependent on the magnitude of the temperature steps between $600^{\circ} \mathrm{C}$ and $800^{\circ} \mathrm{C}$.
Modeling Tritium Processes in PlasmaFacing Beryllium

G. R. Longhurst, R. A. Anderl, T. J. Dolan, and M. J. Mulock, Fusion Technology, 28, October 1995, pp. 1217-1222.

In this paper we present techniques and recommended parameters for modeling tritium implantation, trapping and release, and permeation, in beryllium-clad structures adjacent to the plasma. Among the features that should be considered are the effects of surface films, the mobility of beryllium through those films, damage caused by ion implantation, especially in regions where pitting may be expected, and bubble formation. Tritium transport parameters recommended are based on fits with experimental data and available theory. Estimates of inventories in ITER using these parameters are also given. 


\section{LOW ACTIVATION MATERIALS}

\section{Slag Remelt Purification of Irradiated Vanadium Alloys}

W. J. Carmack, G. R. Smolik, K. A. McCarthy, and P. K. Gorman, INEL95/00324, July 1995.

This paper describes theoretical and scoping experimental efforts to investigate the decontamination potential of a slag remelting process for decontaminating irradiated vanadium alloys. Theoretical calculations, using a commercial thermochemical computer code HSC Chemistry, determined the potential slag compositions and slag-vanadium alloy ratios. The experiment determined the removal characteristics of four surrogate transmutation isotopes $(\mathrm{Ca}, \mathrm{Y}$ - to simulate $\mathrm{Sc}, \mathrm{Mn}$, and $\mathrm{Ar}$ ) from a V-5Ti-5Cr alloy with calcium fluoride slag. An electroslag remelt furnace was used in the experiment to melt and react the constituents. The process achieved about a $90 \%$ removal of calcium and over $99 \%$ removal of yttrium. Analyses indicate that about $40 \%$ of the manganese may have been removed. Argon analyses indicates that $99.3 \%$ of the argon was released from the vanadium alloy in the first melt increasing to $99.7 \%$ during the second melt.

Powder metallurgy techniques were used to incorporate surrogate transmutation products in the vanadium. A powder mixture was prepared with the following composition: 90 wt $\%$ vanadium, $4.7 \mathrm{wt} \%$ titanium, $4.7 \mathrm{wt} \%$ chromium, $0.35 \mathrm{wt} \%$ manganese, $0.35 \mathrm{wt} \%$ $\mathrm{CaO}$, and $0.35 \mathrm{wt} \% \mathrm{Y}_{2} \mathrm{O}_{3}$. This mixture was packed into $2.54 \mathrm{~cm}$ diameter stainless steel tubes. Argon was introduced into the powder mixture by evacuating and backfilling the stainless steel containers to a pressure of 20 $\mathrm{kPa}(0.2 \mathrm{~atm})$. The tubes were hot isostati- cally pressed at $207 \mathrm{MPa}(2000 \mathrm{~atm})$ and $1473 \mathrm{~K}$ to consolidate the metal.

An electroslag remelt furnace (crucible dimensions: $5.1 \mathrm{~cm}$ diameter by $15.2 \mathrm{~cm}$ length) was used to process the vanadium electrodes. A measured quantity of calcium fluoride slag, typically 20 to $25 \mathrm{wt} \%$, was placed in the crucible on a layer of vanadium starting material. The furnace was evacuated prior to heating and backfilled with $33 \mathrm{kPa}$ $(0.33 \mathrm{~atm})$ helium. An arc was struck and the slag heated until a fully molten slag pool developed in the crucible. Power was then adjusted and electrode feed controlled to obtain good melting with currents of 1200 to 1500 amp (voltage ranged from 20 to 28 volts). The vanadium alloy has higher density than the calcium fluoride slag. Therefore, vanadium alloy droplets melted off of the electrode, passed through the molten calcium fluoride slag, and formed an ingot on the bottom of the crucible below the molten slag. Some of the ingots were melted twice to check for additional purification potential.

Slag analyses showed that approximately $0.06 \mathrm{wt} \%$ of the vanadium was lost to the slag. Ingot and slag analysis indicated that $(0.5$ to 10$) \mathrm{wt} \%$ of the chromium and (15 to 50) $w t \%$ of the titanium was lost from the vanadium alloy to the slag.

This work demonstrates that some transmutation isotopes can be removed from vanadium alloys that would be irradiated in a fusion environment. Although this work is preliminary, the data presented here suggest that recycling irradiated alloys by electroslag remelt techniques is promising. These data can be used to further the understanding of 
activities in irradiated and processed vanadium alloys.

\section{Electroslag Remelt Processing of Irradiated Vanadium Alloys}

W. J. Carmack, G. R. Smolik, and K. A. McCarthy, presented at the Seventh International Conference on Fusion Reactor Materials, Obninsk Russia, September 25-29, 1995, to appear in Journal of Fusion Materials.

This paper describes experimental efforts to investigate the potential of a slag remelting process for reducing radioactivity of irradiated vanadium alloys used in a fusion power pro- duction facility. The experiment determined the removal characteristics of four surrogate transmutation isotopes significant to accident safety expected in a $\mathrm{V}-5 \mathrm{Ti}-5 \mathrm{Cr}$ alloy irradiated under fusion conditions $(\mathrm{Ca}, \mathrm{Y}$ - to simulate Sc, Mn, and Ar). Removal of these isotopes could decrease the accident risk of reprocessing irradiated vanadium and reusing it in fusion reactors. An electroslag remelt furnace was used in the experiment to melt and react the constituents using a calcium fluoride slag. The process achieved $90 \%$ removal of calcium and over $99 \%$ removal of yttrium. Analyses indicate that $40 \%$ of the manganese has been removed. Argon analysis of the refined ingots indicates that $99 \%$ of the argon was removed from the vanadium alloy. 


\section{ACTIVATION PRODUCT CHEMICAL REACTIVITY, MOBILIZATION, AND TRANSPORT}

\author{
A Summary of Oxidation Driven \\ Mobilization Data and Their Use in \\ Fusion Safety Assessments \\ K. A. McCarthy, G. R. Smolik, D. L. \\ Hagrman, and D. A. Petti, presented at \\ the Seventh International Conference on \\ Fusion Reactor Materials, Obninsk \\ Russia, September 25-29, 1995, to \\ appear in Journal of Fusion Materials.
}

We have carried out experiments to simulate accident conditions with air or steam ingress, and determine the amount of material mobilized from the material. We also perform first principles modeling to understand the mechanisms involved in mobilization, and determine whether volatilization or oxide spalling dominates mobilization. Our results indicate that if long-term accident temperatures are kept below $\sim 700^{\circ} \mathrm{C}$, oxidation-driven mobilization may be less important than resuspension of tokamak dust, release of corrosion products, and release of plasmavaporized material. 


\section{FUSION SAFETY COMPUTER CODE DEVELOPMENT}

MELCOR EX-Vessel LOCA Simulations for ITER

M. J. Gaeta, B. J. Merrill, H.-W. Bartels and L. Topilski, 16th Symposium on Fusion Engineering, Urbana, IL, September 30-October 4, 1995.

Ex-vessel Loss-of-Coolant-Accident (LOCA) simulations for the International Thermonuclear Experimental Reactor (ITER) were performed using the MELCOR code. The main goals of this work were to estimate the ultimate pressurization of the heat transport system (HTS) vault in order to gauge the potential for stack releases and to estimate the total amount of hydrogen generated during a design basis ex-vessel LOCA. Simulation results indicated that the amount of hydrogen produced in each transient was below the flammability limit for the plasma chamber. In addition, only moderate pressurization of the HTS vault indicated a very small potential for releases through the stack.
CHEMCON User's Manual Version 3.1

M. J. Gaeta and B. J. Merrill, INEL-95/0147, September, 1995.

CHEMCON is a computer program developed to analyze thermal transients of tokamak fusion reactors. It contains a one dimensional, cylindrical geometry, conduction model that allows a variety of heat transfer modes within nodes and at node boundaries. Solid regions can be grouped into segments that communicate at their boundaries through a radiation enclosure model. CHEMCON includes a single volume, pressurization/ condensation model that is used to include the effects of an in-vessel LOCA and the resulting heat transfer between hot surfaces and cold surfaces in contact with this volume. The code includes properties for 11 solid materials and two gases. CHEMCON also contains specialized models for modeling chemical reactions of node boundaries with air and steam including the gases produced from these reactions. In addition, a model treating the collapse of radiation shields within a gap is also included. CHEMCON is used mainly to simulate the thermal transient for post-blowdown loss-ofcoolant-accidents. 


\section{RISK ASSESMENT}

Time-to-Burnout Data for a Prototypical ITER Divertor Tube During a Simulated Loss of Flow Accident

T. D. Marshall, R. D. Watson, J. M. McDonald, L. S. Wold, D. L. Youchison, and L. C. Cadwallader, 16th Symposium on Fusion Engineering, Urbana, Illinois, September 30-October 4, 1995.

The Loss of Flow Accident (LOFA) is a serious safety concern for the International Thermonuclear Experimental Reactor (ITER) as it has been suggested that greater than 100 seconds are necessary to safely shut down the plasma when ITER is operating at full power. In this experiment, the thermal response of a prototypical ITER divertor tube was fabricated from oxygen-free high-conductivity copper to have a square geometry with a circular coolant channel. The coolant channel inner diameter was $0.77 \mathrm{~cm}$, the heated length was $4.0 \mathrm{~cm}$, and the heated width was $1.6 \mathrm{~cm}$. The mockup did not feature any flow enhancement techniques, i.e., swirl tape, helical coils, or internal fins. One-sided surface heating of the mockup was accomplished through the use of the $30 \mathrm{~kW}$ Sandia Electron Beam Test System. After reaching steady state temperatures in the mockup, as determined by two Type- $K$ thermocouples installed $0.5 \mathrm{~mm}$ beneath the heated surface, the coolant pump was manually tripped off and the coolant flow allowed to naturally coast down. Electron beam heating continued after the pump trip until the divertor tube's heated surface exhibited the high temperature transient normally indicative of rapidly approaching burnout. Experimental data showed that time-to-burnout increases proportionally with increasing inlet velocity and decreases proportionally with increasing incident heat flux.

\section{An Experimental Investigation of the Post -CHF Enhancement Factor for a Prototypical ITER Divertor Plate with Water Coolant}

T. D. Marshall, R. D. Watson, J. M. McDonald, and D. L. Youchison, 16th Symposium on Fusion Engineering, Urbana, Illinois, September $30-O c t o b e r$ 4, 1995.

In an off-normal event, the water cooled divertor plates of the International Thermonuclear Experimental Reactor (ITER) may experience heat loads beyond their design basis. Or, during accidents, normal heat loads may be accompanied by low coolant pressure and velocity. The purpose of this experiment was to illustrate that during one-sided heating, as in ITER, a copper divertor plate with the proper side wall thickness, at low pressure and velocity can absorb without failing an incident heat flux, $\mathrm{q}_{\mathrm{i}}$, that significantly exceeded the value, $\mathrm{q}_{\mathrm{i}} \mathrm{CHF}$, which is associated with local CHF at the wall of the coolant channel. The experiment was performed using a $30 \mathrm{~kW}$ electron beam test system for heating of a square cross-section divertor heat sink with a smooth circular channel of $7.6 \mathrm{~mm}$ diameter. The heated width, length, and wall thickness were 16,40 , and $3 \mathrm{~mm}$, respectively. Stable surface temperatures were observed at incident heat fluxes greater than the local CHF point, presumably due to circumferential conduction around the thick tube walls when $\mathrm{q}_{\mathrm{i}} \mathrm{CHF}$ was exceeded. The Post-CHF enhancement factor, $\eta$, is defined as the ratio of 
the incident burnout heat flux, $\mathrm{q}_{\mathrm{i}}^{\mathrm{BO}}$, to $\mathrm{q}_{\mathrm{i}} \mathrm{CHF}$. For this experiment, with water at inlet conditions of $70^{\circ} \mathrm{C}, 1 \mathrm{~m} / \mathrm{s}$, and $1 \mathrm{MPa}, \mathrm{q}_{\mathrm{i}} \mathrm{CHF}$ and
$\mathrm{q}_{\mathrm{i}}^{\mathrm{BO}}$ were 600 and $1100 \mathrm{~W} / \mathrm{cm}^{2}$, respectively, which gave an $h$ of 1.8 


\section{APPENDIX B}

Abstracts of Fusion Safety Program ITER Engineering Design Files 


\section{TRITIUM SAFETY}

Deuterium Implantation Studies for Beryllium

R. A. Anderl, ITER/US/94/TE/SA-21, October 12, 1994.

The purpose of this work was to investigate surface material modifications in beryllium, due to deuterium implantation at energies ranging from $\mathrm{keV}$ to sub-keV, for various specimen temperatures and anneal conditions during the implantation. A multitechnique approach was taken in an attempt to develop a better understanding of deuterium ion-induced changes in beryllium and how those changes affect deuterium retention and release. This approach consisted of the following. (1) detailed surface microstructural and microchemical characterization analyses using SEM and depth-profile Auger spectrometry, (2) positron-beam dep th-profile analyses to characterize defects in unimplanted and deuterium-implanted beryllium, and (3) permeation experiments with sub-keV deuterium ions to complement earlier work with $\mathrm{keV}$ ions. For Be specimens implanted under a variety of different conditions (anneal temperature, specimen temperature during implantation, implantation beam energy), SEM analyses indicated that the defect generation and evolution during deuterium implantation were highly dependent on these factors. Auger depth-profile analy ses for $\mathrm{Be}$ specimens revealed differences in surface oxide layer formation and growth that were correlated to both the $\mathrm{Be}$ temperature during implantation and to the energy and flux of the implanting deuterium. Positron-beam depth-profile analyses identified a varying defect structure in beryllium, dependent on the previous anneal history of the material and on the temperature of the material during implantation with energetic deuterium ions. Based on the positron studies, the beaminduced vacancy-defect complexes were estimated to be $1-\mathrm{nm}$ voids for $1-\mathrm{keV} / \mathrm{D}$ implantation into $\mathrm{Be}$ at room temperature. These measurements indicated that beaminduced defects, for beryllium implanted at elevated temperatures, most likely consisted of large stable voids with defect concentrations less than that for material implanted at room temperature. Permeation experiments with both $1 \mathrm{keV} / \mathrm{D}$ and sub-keV (300 eV/D and 100 eV/D) deuterium indicated that deuterium transport and permeation in ion-implanted beryllium was controlled by both beaminduced defects and by surface oxide layers, with surface-oxide layers having a major effect in the sub-keV experiments.

\section{In-Vessel Tritium Source Term for ITER G. R. Longhurst, ITER/US/94/TE/SA-22, October 14, 1994.}

This study is to make a reasonable but conservative estimate of the tritium inventory that may be available for release from the invessel components of ITER. That inventory comes mainly from tritium breeding in the beryllium by energetic neutrons and from implantation in baffles in the region of the divertor throat and in the upper part of the fins in the divertor channels. TMAP calculations show that after two years of continuous operation (discounting periods when the plasma is shut off) the estimated inventory due to implantation is $2.2 \mathrm{~kg}$ and rising. The bred tritium inventory is estimated at $2.8 \mathrm{~kg}$ based on $3 \mathrm{MW}-\mathrm{yr} / \mathrm{m}^{2}$ neutron fluence. It will be proportional to the neutron fluence, most of which is assumed to come at the end of the machine life. The greatest part of both these inventories will be in divertor components and baffles, which are estimated to be changed out several times during the lifetime of the machine, so the estimates arrived at are expected to be very conservative. 
Essentially all of the tritium inventory will be released if the surface temperature exceeds a temperature between 600 and $650^{\circ} \mathrm{C}$ for periods of more than a few hours. Present thinking is that temperatures may not exceed $500^{\circ} \mathrm{C}$ in an accident in which case only a few percent of the total tritium inventory would be released, apparently with an activation energy of $0.8-1 \mathrm{eV}$. The chemical form of the release will be dependent on the atmosphere inside the vacuum vessel during the accident. If steam reacts with beryllium to leave excess hydrogen or if the atmosphere is vacuum or inert, the released tritium will probably be elemental. If there is free oxy gen present, such as with an air ingress, then the tritium will be mostly oxidized.

This study reviews the configuration and operating conditions assumed in the analysis and the factors that will influence the inventory that will be built up. The structure is assumed to be beryllium cladding on a copper alloy substrate, supported in some components by a stainless steel structure. A major uncertainly is the particle flux to the plasma-facing surfaces and their energies and heat flux distributions. Surface conditions will strongly influence inventory. With the estimate that most of the plasma-facing component surface will only be exposed to very low energy ions and charge-exchange neturals, having energies of less than $5 \mathrm{eV}$, we conclude that erosion and sputtering will be insignificant over most of the surface. Calculated inventory from implantation was insignificant in those areas. On the baffles and on the upper part of the extreme outboard and inboard fins, there will be substantial erosion and surface modification that may include pitting. A key feature revealed by experiments is that deuterium and tritium are expected to build up to an atom fraction of 0.2 or 0.3 in the exposed surface, but then it will saturate and rise no higher. We need to learn more about what is taking place in the implantation region and how to model surface release kinetics during an accident, when the plasma is off. The layer of oxide and other contaminants on the surface of the beryllium, even under intense plasma loading, will have a dominant effect on implanted tritium inventory. Processes important in this region are not well known. Even though the estimates made here are consistent with observation and theory, this is an area that needs much further study.

Temperatures of operation will be moderately high, implying that much if not most of the tritium in the plasma-facing material may be continually exuded as it is formed or trapped. That makes the estimate of inventory mentioned above quite conservative. This aspect needs further investigation. That may be possible on material that has been irradiated in fission reactors to high fluences at elevated temperatures and in experiments using the Tritium Plasma Experiment at LANL or similar facilities.

\section{ITER In-Vessel Tritium Source with Graphite and Tungsten Plasma Facing Components \\ T. J. Dolan, ITER/US/95/TE/SA-5, March 29, 1995.}

An earlier report estimated the tritium inventory for the ITER base case with all beryllium plasma facing components (PFC). Here we consider alternate cases where graphite or tungsten are used for high heat flux areas ( $\mathrm{q}>1 \mathrm{MW} / \mathrm{m}^{2}$.) The variation of heat flux around the wall and divertor surface is estimated, as an input to the TMAP4 code, that computes temperature profiles and tritium transport within the armor tiles. For both cases, only $6 \%$ of the PFCs are graphite or tungsten, and about $94 \%$ of the PFCs remain beryllium. Tritium breeding by neutron ab- 
sorption in the beryllium results in several hundred grams of tritium.

For graphite tiles the processes of tritium implantation, trapping on internal porosity, diffusion into grains with trapping on defects, and codeposition are considered. The dominant mechanism is codeposition, which can contain about $2 \mathrm{~kg}$ of tritium per 1000 pulses of the reactor, and tritium breeding in the beryllium by neutron absorption. For tungsten the processes of implantation, diffusion, and trapping in defect sites are considered. The dominant tritium retention mechanism is trapping, but only 4 grams of tritium are trapped.

Additional information is needed on the ITER tile configuration, wall power flux and particle flux distributions, and particle energy spectra. A computer code like REDEP is needed to model the tritium codeposition rate and distribution with graphite tiles. The effect of neutron irradiation on tritium trapping in tungsten needs to be assessed.

In conclusion, the tritium trapping with graphite by codeposition is large and not well quantified, while the tritium trapping by tungsten is only a few grams.

\section{Deuterium Implantation Studies for $\mathrm{Cu}$, CuCrZralloy, and Cu/Be Composites}

R. A. Anderl, R. J. Pawelko, and M. R. Hankins, EDF No. ITER/US/95/TE/SA4(Rev. 1), May 5,1995.

The purpose of these studies was to perform scoping tests to obtain hydrogen/tritium transport data for an ITER-relevant $\mathrm{CuCrZr}$ alloy of copper $(98.7 \% \mathrm{Cu}, 1.1 \% \mathrm{Cr}, 0.1 \% \mathrm{Zr})$, pure copper and bi-layered structures of cop- per on beryllium. The approach taken was to perform deuterium implantation/permeation experiments and post-implantation thermal desorption experiments on selected samples of the above materials, along with extensive materials characterization and TMAP4 calculations to simulate the measured re-emission and permeation results. Permeation measurements were made for $\mathrm{CuCrZr}$ over the temperature range from $700 \mathrm{~K}$ to $780 \mathrm{~K}$, using a $3-\mathrm{keV} \mathrm{D}_{3}{ }^{+}$ ion beam with fluxes of $6 \mathrm{E} 19$ to $7 \mathrm{E} 19 \mathrm{D} / \mathrm{m}^{2} \mathrm{~s}$. Effective diffusivities and surface molecular recombination coefficients were obtained from analyses of the experimental data, and the derived Arrhenius parameters (pre-exponentials and activation energies were: diffusivity $(2.0 \mathrm{E}-$ $02 \mathrm{~m}^{2} / \mathrm{s}, 1.2 \mathrm{eV}$ ) and recombination coefficient $(2.9 \mathrm{E}-14 \mathrm{~m} / \mathrm{s}, \quad 1.92 \mathrm{eV})$. Permeation measurements were made for $\mathrm{OFHC}-\mathrm{Cu}$ for similar temperatures and ion-beam conditions. Arrhenius parameters derived from analysis of the pure $\mathrm{Cu}$ experiments were: diffusivity $\left(2.1 \mathrm{E}-06 \mathrm{~m}^{2} / \mathrm{s}, 0.52 \mathrm{eV}\right)$ and molecular recombination $\left(9.1 \mathrm{E}-18 \mathrm{~m}^{4} / \mathrm{s}, 0.99 \mathrm{eV}\right)$. Materials characterization and permeation measurements were made for $\mathrm{Cu} / \mathrm{Be}$ bi-layer specimens that comprised sputter-deposited copper coatings (1-micrometer and 5-micrometer) on high purity $\mathrm{Be}$ foil specimens. Permeation measurements were made with the $3-\mathrm{keV} \mathrm{D}_{3}{ }^{+}$beam, (particle flux of $5.6 \mathrm{E} 19 \mathrm{D} / \mathrm{m}^{2} \mathrm{~s}$ ) incident on the copper surface rather than the Be surface, to avoid the influence of beam-induced damage in the $\mathrm{Be}$ and to obtain information to test the influence of the $\mathrm{BeO}$ interface between the $\mathrm{Cu}$ coating and the Be substrate. The measured permeation data were compared to TMAP4 calculations in which the $\mathrm{Cu} / \mathrm{Be}$ specimen was modeled as a four-layer structure: $\mathrm{Cu}$ coating/BeO interface/ $\mathrm{Be}$ bulk/BeO downstream surface layer. A reasonable simulation of the measured data was achieved using currently recommended values for deuterium solubility and diffusivity in $\mathrm{Be}, \mathrm{BeO}$, and $\mathrm{Cu}$. 
Assessment Of Database For Tritium Interaction With Tungsten

T. J. Dolan and R. A. Anderl, ITER/US/95/TE/SA-17, June 211995

The literature on hydrogen interaction with tungsten is summarized. Tritium behavior in tungsten is fairly well understood, compared with some other plasma facing materials. Oxide layer, porosity, and grain boundary effects do not appear to be dominant in tungsten like they are in $\mathrm{Be}$ and $\mathrm{C}$. The database for tritium behavior in tungsten is good in the areas of diffusion, solubility, permeation, and trapping. It appears that the tritium inventory in tungsten will be very low, unless neutron damage produces high concentrations of trap sites. More research is needed to quantify neutron irradiaton effects on tritium trapping and to measure the thermomigration energy $Q^{*}$.

Test Plan for Source Term Data, Modeling, and Analysis - Subtasks 2 and $4 a$

T. J. Dolan, R. A. Anderl, and G. R. Longhurst, ITER/US/95/TE/SA-13 REV 01 August 10, 1995

This test plan covers work to be performed in the area of tritium source term as part of ITER Task S 81 TT 08 95-02-28 FU.
Specifically this task supports quantification of inventories, permeation, and mobilization fractions of tritium in plasma-facing-component (PFC) materials during accidents (Subtask 4a); and provides TMAP4 code user support, documentation, configuration control, and system modeling for ITER (Subtask 2). These tasks build on 1994 NID tasks NID-5b and 5f (S 71 TT 49 and S71 TD 54). Emphasis of the work is on tritium behavior in plasma-facing component materials during accident scenarios. Materials considered in this work include the key ITER-relevant materials (Be, $\mathrm{C}, \mathrm{W}, 316 \mathrm{SS}$, and $\mathrm{Cu}$-alloys) and combinations of these materials that simulate the complex deposits in operating tokamaks. In addition the influence of neutron irradiation effects on tritium behavior is considered where appropriate. Experimental measurements, data assessment and analytical/modeling studies will be done, with key results being tritium inventory and mobilization fractions corresponding to relevant accident conditions. These results will be used in safety assessments, in sitesuitability source term envelope determinations and as input to the ITER Non-Site Specific Safety Report (NSSR). This plan, which runs from January 1995 to June 1998 ( 3.5 years), will be reviewed annually and updated as needed. 


\section{ACTIVATION PRODUCTS AND CHEMICAL REACTIVITY}

Models for Mobilization of $\mathrm{Zn}, \mathrm{Co}$, and Fe from Copper Alloy

D. L. Hagrman, ITER/US/95/TE/SA-2, February 6, 1995

The purpose of the activation products task at the Idaho National Engineering Laboratory (INEL) is to provide information about the mobilization and transport of activated materials (and beryllium because of its toxicity) under accident conditions in fusion reactors. Part of the mobilization information needed is a data base for use in the regulatory process for ITER. Another need is an appropriate method to apply the data base to ITER. This Engineering Design File (EDF) describes progress toward providing models for mobilization of zinc, cobalt, and iron from copper alloy.

The models are based on experimental data from the VAPOR facility in both steam and air environments. Analysis of the data shows that the primary means of mobilization of these three elements in pure steam is volatilization. In the presence of sufficient oxygen to form (and maintain) an oxide layer on the copper alloy, stochastic oxide spalling after the high temperature portion of the experiments was the dominant mobilization mechanism. Zinc and cobalt mobilization rates were somewhat higher in steam than in air but the mobilization rates of iron were similar in air and steam.

Detailed models for the volatilization of zinc, cobalt, and iron in steam are provided in the body of this Engineering Design File. The models assume that the rate of volatilization of these elements is controlled by diffusion to the alloy surface, the equilibrium concentration of hydroxides of the elements that are formed at the surface, and the mass transport of the hydroxide compound to the bulk gas stream.
This mechanism implies a strong coupling between the volatilization of the species because the hydrogen produced by the reaction of one of the copper alloy elements with water vapor reduces the equilibrium concentration and volatilization rate of another element of the alloy. There would also be a strong coupling to any other source of hydrogen such as reaction of alloys other than copper with steam if the hydrogen produced by these other sources is transported to the copper alloy surface.

We are not yet able to produce a tractable model for spalling because of the complex nature of the oxide layer stresses that cause spalling. Moreover, it is unlikely that the stresses produced in cooling laboratory scale samples are the same as the stresses produced in full scale surfaces. Therefore, we recommend that it be assumed for modeling purposes that all of the elements that were in the oxide layer formed on the copper alloy are mobilized when the copper alloy cools. These amounts vary from one to as much as a hundred times the mobilizations measured but they are typically not more than the mass that is volatilized in steam during one and five hour tests.

The models we propose imply that characterizing mobilization with a flux may be misleading when the mobilization is primarily due to spalling. The amount of oxide formed on copper in air is proportional to the square root of time and the rate of formation is inversely proportional to the square root of time after a brief initial period when the formation rate is limited by the transport of oxygen to the alloy surface. Projections of the measured mobilization beyond the 20 hour maximum time span of the measurements using the oxidation model yield predictions that are considerably less than projections using a constant flux. Another reason a flux may be misleading 
is that the spalling probably occurs at the end of the time at high temperature, not throughout the high temperature span.

The most useful additional measurements identified by the analysis would be a series of long experiments in air with larger samples than those used in the current experiments. There is some indication that the thicker oxides do not spall as much as the thinner ones. If this trend can be confirmed and be shown to be applicable to larger surfaces more characteristic of fusion machines, it would not be necessary to assume that the entire oxide layer spalls in order to be sure that the model results are defensible. Examination of the oxide spalled from both small and larger samples would provide a preliminary indication of the effect of sample size on the size distribution of the spalled oxide pieces.

It would also be useful to conduct experiments with some hydrogen added to a steam source to test the theoretical prediction that hydrogen from a source other than the copper alloy should inhibit volatilization of cobalt, iron, and perhaps zinc in steam.

\section{Activation Product Source Term for ESECS \\ K. A. McCarthy, ITER/US/95/TE/SA-6, March 30, 1995.}

The purpose of this EDF is to provide the activation product source term to be used by the JCT in preparing input for the Early Site and Environmental Characterization Study (ESECS). The source term developed here is based on experiments carried out by the Fusion Safety Program at the Idaho National Engineering Laboratory (INEL). The information used to develop the source term was put into spreadsheet form. This allows the user to calculate a variety of cases, and provides flexi- bility so that the spreadsheet can be used to calculate new cases when parameters have changed.

We provide background information on our test procedure, a description of how the data is used in the source term calculation, and examples of the activation product source term for four materials: tungsten, dispersionstrengthened copper, 316SS, and Inconel 625. Three dose scenarios (four types of dose from each scenario: dose from plume passage, early dose, chronic dose without ingestion, and chronic dose with ingestion), three fluences $\left(0.3,1.0\right.$ and $\left.3.0 \mathrm{MW}-\mathrm{yr} / \mathrm{m}^{2}\right)$, and two accident environments (air and steam) are provided in the spreadsheet. Additionally, the user can input his or her own activation calculation and/or dose information.

The source term calculations were verified against other available information.

\section{Aerosol Transport Through ITER Ducts D. L. Hagrman, ITER/US/95/TE/SA-7, April 3, 1995.}

Aerosol transport calculations have been performed to determine the retention and transport of aerosols through ITER ducts in the event of an overpressure that ruptures the barriers that normally isolate the vacuum vessel from the tokamak building. This work provides the technical basis for establishing the source term to confinement barriers for accidents that breach the vacuum vessel and bypass the cryostat.

A small duct representing one radio frequency waveguide and a larger duct representing one neutral beam injection system were considered. The gas speed and temperature in these ducts for a number of pressure 
differences and lengths were determined. These thermal hydraulic parameters were then used to determine release fractions.

Most of the gas was found to exit the ducts at speeds of hundreds of meters per second (only the gas driven by small residual pressure differences had lower speeds). At these speeds, aerosol particle deposition is dominated by particle diffusion due to turbulent flow (particle mobility and eddy diffusion). Key parameters for this kind of particle deposition are the duct surface roughness, the diameter of the duct, and particle inertia which tends to keep particles in the bulk flow.

For the small waveguide duct with corrugated surfaces (surface roughness of 0.4 $\mathrm{mm}$ ) the calculations indicate small release fractions of 0.08 at $400 \mathrm{~m} / \mathrm{s}, 0.07$ at $300 \mathrm{~m} / \mathrm{s}$, 0.06 at $200 \mathrm{~m} / \mathrm{s}, 0.05$ at $100 \mathrm{~m} / \mathrm{s}$, and 0.04 at $50 \mathrm{~m} / \mathrm{s}$. In the large duct, the calculations show particle inertia limits deposition so that transmission fractions of 0.82 to 0.86 are calculated for particles larger than $0.3 \mu \mathrm{m}$ in diameter and nearly one for smaller particles.

\section{Test Plan for Chemical Reactivity Task, ITER Task: S 81 TT 14 95-02-28 FU ITER/US/95/TE/SA-8, K. A. McCarthy, May $1,1995$.}

The thermal decay heat and the potential chemical energy within ITER are sufficiently large to be of concern. At sufficiently high temperatures, the beryllium first wall armor can react with steam to produce significant amounts of hydrogen gas. The chemical reactivity of $\mathrm{Be}$ is extremely sensitive to the form of the Be. Previous tests at the INEL on three types of $\mathrm{Be}$, fully dense, $88 \%$ dense, and plasma-sprayed show that reaction rates can differ by two orders of magnitude. For this reason, a series of tests are necessary to characterize the chemical reactivity of $\mathrm{Be}$ and extrapolate those results to tokamak-condition $\mathrm{Be}$.

This task (S 81 TT 14 95-02-28 FU) provides the basic data on chemical reaction rates and the associated hydrogen production (in the case of reactions with steam) for four types of beryllium: irradiated, plasmasprayed, porous, and fully dense. It also provides for incorporation of this data into the one-dimensional and two-dimensional heat transport codes used to determine the thermal response of the ITER blanket, vacuum vessel and associated structures during a LOCA. This task is a follow-on to work performed in 1994 under task NID-7b.

The Russian Federation HT is also involved in this task. David Petti is the task coordinator for this task. If Be dust is tested, the RF home team will do that testing, in addition to other forms of non-irradiated $\mathrm{Be}$.

\section{Modeling Transport of Aerosols from PCA Steel Alloy}

D. L. Hagrman, ITER/US/95/TE/SA-11, May 15, 1995

The activation products task at the Idaho National Engineering Laboratory (INEL) exists to provide information about the mobilization and transport of activated materials and beryllium (because of its toxicity) under accident conditions. Part of this task is to develop and demonstrate appropriate methods to apply the data base generated by experiments to ITER. This Engineering Design File (EDF) describes and demonstrates methods developed for the analysis of transport experiments with heated PCA steel samples in the VAPOR facility. 
The experiments and analysis show that aerosols are an important part of the transport of activation products from PCA steel, even if the bulk of the aerosol mass is not an activation product that causes concern from an offsite dose perspective. It is also shown that there are likely to be two general kinds of aerosol particles present, homogeneously nucleated particles and spalled particles. The differences in the nature of these particles will produce noticeable differences in aerosol transport behavior.

In air, molybdenum oxide is volatilized from the steel surface during $1200^{\circ} \mathrm{C}$ exposures and condenses to form an aerosol consisting of very small particles. Manganese and cobalt are present as oxides at the steel surface and do not volatilize significant amounts of vapor because of the low equilibrium vapor pressures of these oxides. However, we believe that a small portion of the oxide spalling consists of particles small enough to be mobile. We also believe, based on tentative evidence from electron microscopy and calculations, that the spalling in air is mostly during cooldown. Tables of the size distribution of spalled oxide per unit surface area for the small-particle end of the size distribution deduced from cascade impactor measurements and particle deposition calculations are presented in this design file. For the tests in air at $1200^{\circ} \mathrm{C}$ we have concluded that about two thirds of the mobile mass was volatilized but almost all of the mobile dose-relevant elements, cobalt and manganese, were associated with spalled particles.

In steam, iron, manganese, and cobalt are volatilized from samples at $1000^{\circ} \mathrm{C}$ but analysis finds the mass of these elements volatilized is only a third of the mass spalled as small, mobile particles in the VAPOR experiments. The volatilized material is mostly $\mathrm{Fe}(\mathrm{OH})_{2}$, $\mathrm{Mn}(\mathrm{OH})_{2}$, and $\mathrm{Co}(\mathrm{OH})_{2}$. However, very small amounts of the oxides of the metals may be formed when these species move away from the steel surface and give off a water molecule. The oxides have such low vapor pressures that they may nucleate particles to form an aerosol in the absence of aerosol particle seeds of some other species. Our modeling calculations found that this did not happen in the VAPOR experiments but the oxide vapors were slightly above equilibrium so nucleation by this method may happen in some circumstances. The presence of very fine particles in the filter of the cascade impactor of the VAPOR experiments suggests that nucleation did occur at some time during the VAPOR experiments and our analysis finds it was the hydroxide that nucleated. The analysis indicates that once a surface was available, the chemical reaction that caused vaporization at high temperatures reversed, causing chemical deposition of an oxide on the aerosol particles at lower temperatures. Small-particle size distributions due to spalling in steam estimated from the measured size distributions at the impactor are presented in this design file.

The small-particle distributions in steam and air are remarkably similar, with the mass spalled in steam being a little greater at smaller particle sizes. Additional data in both steam and air from several different sample sizes, geometries, scale thicknesses, and cooling rates will be needed to determine whether the smallparticle component of the spalling deduced from the VAPOR samples are applicable to other samples. We believe spalling may be a function of the sample cooling rate, size, and oxide plasticity. Also, additional data will be needed to verify the timing of the spalling. 
Test Plan for Source Term Data, Modeling, and Analysis - Subtasks 2 and 4a, ITER Task S 81. TT 08 95-02-28 FU

K. A. McCarthy, ITER/US/95/TE/SA-12, May 16, 1995.

The safety strategy for the activation product source term is to minimize the source term for the four dominant mobilization pathways: (a) oxidation driven mobilization, (b) plasma vaporized material, (c) corrosion products, and (d) tokamak dust. This subtask is to perform detailed focused safety R\&D to ensure that the activation product source term due to oxidation driven mobilization and plasma vaporized material is low enough to meet regulatory dose requirements.

The tolerable activation product release fraction times the mobilization fraction for the total machine must be about $10^{-6}$ under accident conditions. An initial allocation is that the oxidation-driven mobilization fraction must be less than $10^{-3}$ and the confinement release fraction (i.e., the amount of mobilized activation products that are ultimately transported to the environment) must be less than $10^{-3}$.

All tests, modeling, and analysis subtasks are to be focused on ITER materials as will be confirmed in the ITER Interim Design Report (June 1995). These are expected to include $\mathrm{Be}, \mathrm{C}$, and $\mathrm{W}$ as plasma-facing materials, $316 \mathrm{SS}$ and $\mathrm{Cu}$-alloy as divertor/first wall, and Inconel 625 or $316 \mathrm{SS}$ for the vacuum vessel.

We have done a significant amount of work in the area of mobilization and transport since we began experiments in the 1980's. In 1994, we assessed our database and determined where additional data are needed. Our test plan addresses how we will fill these needs. One of our primary aims is to lower detection limits. We were able to do this for Co release from austenitic steel by using a more sophisticated analytical technique. We plan to further lower our detection limits by developing and using a larger source.

This subtask (S 81 TT 14 95-02-28 FU subtask 1) is the technical lead for the entire clustered task. This includes helping the JCT TO (and Task Assistants) integrate the technical information. This clustered task provides the tools, data, and some of the analysis to characterize the source term for ITER. Subtask 1 of this task is a follow-on to work performed in 1994 under tasks NID-4a and NID9c. This EDF gives the test plan for this multi-year task.

\section{Test Plan for Disruption Induced Aerosol Characterization for ITER Source Term Determination J. P. Sharpe and K. A. McCarthy, ITER/US/95/TE/SA-22, September 6 , 1995.}

The present level of ITER engineering design activity (EDA) is appropriate to begin consideration of accident scenario analysis in which radioactive material may be transported to site boundaries. Several mechanisms exist for the mobilization of activated reactor component material; oxidation driven volatilization and spallation, corrosion, dust resuspension, and nucleation of disruptionablated material from plasma-facing components (PFCs) comprise the mobilization pathways of significant concern. Research at the INEL in the Fusion Safety Program is currently focused on volatilization and spallation of various materials. Research is to be performed by North Carolina State University (NCSU) in the area of plasma disruption mobilization of activated material. 
Plasma disruptions occur in a tokamak due to an off-normal event that causes loss of plasma confinement. As confinement is lost, the energy stored within the plasma is directed toward armored wall tiles that act as the sacrificial barrier for other reactor components. This energy dump proceeds in a short duration, with current decay times in the range of tens of milliseconds. Plasma-wall interaction during the thermal quench phase of the disruption will determine the amount of material mobilized and available for transport out of the system in the event of failure of confinement barriers.

The purpose of this research task is to characterize and quantify plasma disruption effects on ITER relevant plasma-facing material (PFM) in relation to activation product mobilization and transport during an accident in which a pathway exists for materials release. Specific modeling of plasma - surface interaction with emphasis on aerosol nucleation and transport is required to derive an accurate source term for disruption-induced mobilization. The model will be developed and benchmarked by experimental verification with data from a disruption simulator, with scaling concerns addressed. The disruptioninduced mobilization source term will be useful in determining fusion reactor safety.

This research subtask is Part B of the ITER Source Term Data, Modeling, and Analysis Task (task number: S 81 TT 14 95$02-28 \mathrm{FU}$ - subtask 1). This subtask is to provide tools, data, and some analysis to characterize the source term for ITER. Part B of this subtask provides tools, data, and analysis specifically for material mobilized during a plasma disruption.

\section{A Medium-Scale Aerosol Source for the INEL Fusion Safety Program W. J. Carmack, ITER/US/95/TE/SA-25, September 15, 1995.}

An experimental facility has been constructed to produce and measure aerosol material from SS 316 , copper, and tungsten materials typically found in fusion reactor systems. Details of the design and fabrication of the facility are presented including aerosol production and measurement equipment, effluent control, and data analysis.

The facility is capable of operation up to $1200{ }^{\circ} \mathrm{C}$ at standard pressures. A variety of flow rates can be maintained in the experiment depending upon the orientation of aerosol instruments using steam, air, or a combination of the two. The facility is flexible and capable of being used for volatility and mobilization experiments as well as functioning as a medium scale aerosol source for future transport experiments. Below is a summary of current system capabilities. These parameters may be increased for future experiments.

\begin{tabular}{|l|l|l|}
\hline $\begin{array}{l}\text { Temperature } \\
\text { Range }\end{array}$ & 0 to 1200 & ${ }^{\circ} \mathrm{C}$ \\
\hline $\begin{array}{l}\text { Steam } \\
\text { Flow Rate }\end{array}$ & 27 & $\begin{array}{l}\operatorname{lpm}(\mathrm{at} \\
\left.100^{\circ} \mathrm{C}\right)\end{array}$ \\
\hline Air Flow Rate & $0-50$ & $\mathrm{lpm}$ \\
\hline System Pressure & $0-202$ & $\mathrm{kPa}$ \\
\hline $\begin{array}{l}\text { Particle Size } \\
\text { Analysis } \\
\text { (Particle Mass) }\end{array}$ & 0.003 to $>12$ & $\mu \mathrm{m}$ \\
\hline $\begin{array}{l}\text { Particle Size } \\
\text { Analysis } \\
\text { (Particle Number) }\end{array}$ & 0.003 to $>12$ & $\mu \mathrm{m}$ \\
\hline
\end{tabular}


Transport Investigation of Oxidized 316 SS and Copper Alloy

G. R. Smolik, ITER/US/95/TE/SA-26, September 22, 1995

The purpose of this task at the Idaho National Engineering Laboratory (INEL) is to provide experimental information about the mobilization and transport of oxides from 316 stainless and a copper alloy. Previous tests have shown that spalled oxide has played a significant role in the mobilization of various elements from these alloys tested in air and steam. This series of experiments was planned to provide more specific information about the time when oxide spalling occurs and about the size distribution of the spalled oxides. The information from these experiments will be used to support the modeling activities at the INEL that address the mobilization and transport of activation products during potential fusion reactor accidents.

An experimental test system was set up with a valve to control the flow of the test gases, air or steam, during the cool down period of the experiment. The flow could be directed through a cascade impactor or be diverted to another filter during cool down. This allowed us to establish the time at which oxide spalling predominantly occurred. In addition to the cascade impactor, particle sizes were determined by screening and with a particle size analyzer. The amounts and size distributions of the oxides spalled from 316 stainless steel and the copper alloy were thereby established.

We have found that some oxide spalling can occur during the growth stages of the oxide scale during the isothermal portion of the exposures. However, most of the spalling, probably eighty percent occurs during cool down. In addition, we found that the spalled oxide was composed generally of fairly large particles. More than $80 \%$ was over $250 \mu \mathrm{m}$ in size. The 316 stainless steel showed that only 0.5 and $1.5 \%$ of the mass of spalled oxide was below $10 \mu \mathrm{m}$ and $20 \mu \mathrm{m}$, respectively. Even fewer particles of these small sizes were generated when oxide spalled from the copper alloy after exposures in air. Larger amounts of such particle sizes were formed when the copper alloy was exposed in steam. The percentages of spalled oxide below $10 \mu \mathrm{m}$ and $20 \mu \mathrm{m}$ were 2.3 and 5.7, respectively. The amounts of mobilization that occur by volatilization of elements or compounds having low vapor pressures are small compared to those occurring by the spalled oxides. Thus, from a modeling standpoint the large oxide particles, and their generation at the end of the test, cause them to be unimportant to nucleation (seeding) or growth processes during transport. The models appropriately predict the very small, submicron particles nucleated and grown from vapors (We have observed such particles with electron microscopy). The amount of these vapor generated aerosols and small (i.e., $<10 \mu \mathrm{m}$ ) spalled particles is small compared to the total spalled oxide for these two alloys. We estimate that they represent only $0.5-3 \%$ of the total oxide spalled. These experiments show that our previous mobilization measurements have been largely derived from larger particles, i.e., $10-250 \mu \mathrm{m}$. These particles are too large to be transported as aerosols and will settle, be attracted to system walls, or be easily filtered. Our mobilization measurements thus provide calculated dose contributions that are conservatively high, probably by a factor of about 100, for elements that are not mobilized by volatilization. 
Mobilization During the Oxidation of Inconel-625

G. R. Smolik, ITER/US/95/TE/SA-27, September 22, 1995.

We have tested samples of Inconel 625 in high temperature $\left(600-1200^{\circ} \mathrm{C}\right)$ flowing air to evaluate the mobilization of various elements during oxidation. Inconel 625 has a higher chromium content, i.e., $21 \mathrm{wt} \%$, compared to $16-18 \mathrm{wt} \%$ in the austenitic stainless steels previously tested for fusion applications. This higher chromium content resulted in the development of a protective chromia scale. The chromia scale remained protective for up to five hours at $1200^{\circ} \mathrm{C}$. The amount of oxide formed on Inconel 625 at $1200^{\circ} \mathrm{C}$ was less than one-tenth of that formed on 316 stainless steel. In addition, smaller amounts of the oxide scale spalled from the Inconel, i.e., less than 2 percent compared to over eighty percent for 316 stainless steel. Also, less of the spalled oxide particles were sufficiently small to remain airborne and transportable. since the oxide scale was basically $\mathrm{Cr}_{2} \mathrm{O}_{3}$, mobilization rates for chromium were about equivalent to those observed from the mixed spinel oxides ( $\mathrm{Fe}, \mathrm{Cr}, \mathrm{Ni})_{3} \mathrm{O}_{4}$ formed on PCA, a modified 316 stainless steel. Mobilization of other elements, even molybdenum with the very volatile $\mathrm{MoO}_{3}$, were restricted by the chromia scale. Mobilization rates measured for these elements including iron, nickel, manganese, molybdenum, phosphorous, titanium, and cobalt were from 1 to 3 orders of magnitude lower than those measured for PCA steel. Very low mobilization rates, $2 \times 10^{-8}$ to $4 \times 10^{-6}$ $\mathrm{g} / \mathrm{m}^{2} \mathrm{~h}$, were measured for tantalum. The lower mobilization rates for the various elements, many of which are critical from an activation standpoint, resulted despite their higher concentrations in Inconel 625 compared to PCA steel. The low mobilization rates measured in this study indicate that for temperatures of up to $1200^{\circ} \mathrm{C}$ and times of up to five hours mobilization of activation products from Inconel 625 would be less than those occurring from austenitic stainless steels with $16-18 \mathrm{wt} \%$ chromium. 


\section{RISK ASSESSMENT}

Vacuum Vessel Failure Modes and Effects Analysis and Suggested Penetration Failure Rates for the International Thermonuclear Experimental Reactor

L. C. Cadwallader, ITER/US/94/TE/SA-23, December 16, 1994.

This EDF discusses a preliminary Failure Modes and Effects Analysis (FMEA) for the vacuum vessel and gives suggested failure rates for vacuum vessel penetrations, such as bellows, windows, and ceramic electrical feedthroughs. In general, the concerns with the vacuum vessel are that the vessel is built robustly enough to not need any repairs over its 20 year lifetime. The penetrations have two concerns, leakage in normal operation and maintaining integrity in off-normal operation. There are no data to support making good judgments of penetration reliability at the present time. When ITER components are more completely designed, then better estimates of component resiliency to overpressure events can be made. This work should be revisited when more design information has been published. The overall results of the penetration failure rate study are that the bellows can be manufactured to easily exceed the expected 0.4 to $0.5 \mathrm{MPa}$ overpressures generated by invessel pipe ruptures, so the failure rates should be low and adequate numbers of bellows can be used. If the preliminary extrapolations from failure rates of alumina-insulated spark plugs apply to the much larger ITER penetrations, then perhaps 100 large ceramic instrumentation feedthroughs can be used while still meeting the vacuum vessel overpressure failure rate of $1 \mathrm{E}-03$ to $1 \mathrm{E}-04$ per demand. The information found on windows is not so optimistic. If the windows survive the 0.4 to $0.5 \mathrm{MPa}$ overpressure, then they would probably lose strength during the overpressure stress event, and they would probably need to be replaced before the machine could operate again. Limiting peak pressure, using redundant windows, or possibly using gate valves in the window ports should be investigated for feasibility. This engineering design file satisfies two milestones for the US contribution to Nuclear Integration Division tasks $3 \mathrm{~b}$ and $9 \mathrm{~b}$. Both of these milestones were due at the end of December 1994. As mentioned above, this task should be revisited when more design information on penetrations has been distributed.

\section{Preliminary Failure Rates for Selected ITER Safety Systems}

L. C. Cadwallader, ITER/US/94/TE/SA-24, December 16, 1994.

This EDF discusses preliminary failure rates for the suggested passive stack cleanup system, the plasma shutdown system, and the rupture disk overpressure vent system for the vacuum vessel. The stack cleanup system includes blow out panels in the Heat Transport System vault rooms, ducts to route steam flow, scrubbers and dryers to remove particulates and tritium, filters, and the vent stack. The plasma shutdown system is not well defined, so the discussion contained analogies to the reliability of other safety systems. The rupture disk information was taken from the literature. This information should support the ITER Early Safety and Environmental Characterization Study (ESECS). There is no fiscal year 1995 milestone for this task, it is added work requested by the San Diego Joint Work Site. 


\section{Preliminary Estimates of Frequencies for Reference Postulated Initiating Events \\ L. C. Cadwallader, ITER/US/94/TE/SA- \\ 25, December 16, 1994.}

This EDF discusses a preliminary quantification of selected initiating event frequencies for the reference postulated initiating events (RPIEs) that will be used in the Early Safety and Environmental Characterization Study (ESECS). The events considered are Loss of Power Supply, Rupture of a First Wall-Shield Blanket Coolant Loop outside the Vacuum Vessel, Rupture of a heat exchanger tube in the First Wall-Shield Blanket Coolant Loop, Rupture of All Outboard First WallShield Blanket cooling segments inside the vacuum vessel, Rupture of a Divertor Coolant Loop outside the cryostat, Leak of One Divertor Tube inside the Vacuum Vessel, Leakage of One Vacuum Vessel cooling segment into the Vacuum Vessel, Leakage of One Loop of the Vacuum Vessel cooling circuit into the Cryostat, Rupture of All Loops inside the Cryostat, and a Generic Small Loss of Coolant Accident in the Vacuum Vessel. The preliminary quantification is based on design information presented at the ITER Design Review meeting in San Diego, October 17-28, 1994. This work does not have a milestone for fiscal year 1995, it is an additional task that falls into the "on-call assistance" category for support to the ITER San Diego Joint Work Site.

\section{Vacuum Vessel Reliability Issues}

L. C. Cadwallader, ITER/US/94/TE/SA-26, December 23, 1994.

This EDF primarily discusses weld reliability for the ITER vacuum vessel. Types of advanced welding, the problems facing Inconel welding, and weld quality assurance methods are discussed. This information may be used in the Early Safety and Environmental Characterization Study (ESECS). With advanced welding techniques (electron beam or laser beam welding), use of newer weld inspection methods (radioscopy), and three dimensional computer analysis of the weldments before they are made, there should be adequate reliability over the life of the project. This work does not have a milestone for fiscal year 1995 , it is an additional task that falls into the "on-call assistance" category for support to the ITER San Diego Joint Work Site.

\section{Revision to Chi/Q Data Files in the U.S. Computerized Dose Worksheet (Scoping Tool) \\ M. L. Abbott, ITER/US/95/TE/SA-01, February 2, 1995.}

This engineering design file (EDF) documents the creation of two new Chi/Q files for use in the International Thermonuclear Experimental Reactor computerized dose worksheet or "scoping tool" (Abbott et al., 1993). These new Chi/Q values correct the scoping tool outputs for more appropriate building wake effects, to provide more accurate dose estimates at close proximity to the facility vent stack; and the second file treats wind effects at $10 \mathrm{~m}$ altitude, not the stack height altitude of $100 \mathrm{~m}$, to better evaluate the actual maximum dose possible at a given distance, regardless of the atmospheric stability conditions. Therefore, Chi/Q files are only needed for the case 1, which is an elevated stack release without treatment of rain. This EDF is accompanied by electronic transmission of Chi/Q data files for those scoping tool users. The paper copy of this EDF is provided for documentation to those ITER personnel not actively using the scoping tool. 
Preliminary Component Taxonomy for the International Thermonuclear Experimental Reactor Engineering Design Activity

L. C. Cadwallader, ITER/US/95/TE/SA-07, April 28, 1995.

This EDF discusses a preliminary listing of components which will require reliability information to support the Non Site-specific Safety Report (NSSR) and other safety documentation for the International Thermonuclear Experimental Reactor (ITER) design project. The list is tentative and will need revision as the design process matures and as the NSSR accident analyses are begun. Components to focus on will be agreed upon in close cooperation with Dr. A. Poucet, the Task Officer at the ITER San Diego Joint Work Site. These data collected by all Parties in the ITER project will be stored in a computerized data base kept by the US Home Team. This data bank will be open to all ITER participants. The data bank will be set up and entries will begin in late 1995. A preliminary division of labor among the home teams is also discussed in this EDF.

Research and Development Plan for Plant Level Safety Assessment Tools and Data Task (S 81 TT 11)

L. C. Cadwallader, ITER/US/95/TE/SA-10, May 2, 1995.

This EDF discusses the research and development plan that the US. Home Team will follow for the plant level safety assessment tools and data task from the Joint Central Team. The US Home Team will take the lead in generating component failure rate data for use in the safety tasks, such as for the Non Site-specific Safety Report (NSSR). This data collection task will operate at a continuous but modest level of effort through January 1998. Components to focus on will be agreed upon in close cooperation with Dr. A. Poucet, the Task Officer at the ITER San Diego Joint Work Site. These data, collected by all Parties in the ITER project, will be stored in a computerized data base kept by the US Home Team. The data bank will be set up and entries will begin in late 1995 .

\section{Proposed US Annotated Table of Contents for the ITER Non Site-specific Safety Report (NSSR)}

L. C. Cadwallader, ITER/US/95/EN/SA01, May 15, 1995.

This EDF discusses the expected content of the ITER Non Site-specific Safety Report. The chapters are expanded with notes to give guidance on what the US expects to be included in the chapters. Suggested numbers of pages for each chapter are also given to the right of the chapter titles. Overall, there are about 350 pages anticipated for this report. In preparing this annotated outline, we followed the US guidance found in Department of Energy (DOE) Standards 1027 (1992) and 3009 (1994), and direction in DOE Order 5480.23 (1992). These three documents address the scope, content, analysis depth, and comprehensiveness of safety analysis reports; and these reports have already been provided to the ITER Joint Central Team. The appropriate sections of a DOE Safety Analysis Report are mapped into the NSSR chapter headings on the following page, and this table was the basis for our notes under the NSSR chapter headings. Several of the DOE chapters are not covered: Site Characteristics (site specific; not possible in an NSSR), Inadvertent Criticality Protection (not required), Human Factors (too early in the design to include this, but it will be necessary for a final SAR), Emergency Preparedness Program (site specific), and Provisions for Decontamination and Decommissioning (site specific). This annotated table of contents is the US representation of what should 
be included in the NSSR to satisfy US DOE requirements. This EDF is the US contribution to the process of building a quadrilateral Home Team consensus on the NSSR contents.

Preliminary Taxonomy of Components and Failure Modes for the ITER EDA

L. C. Cadwallader, ITER/US/95/TE/SA-21, August 28, 1995.

This EDF discusses the classification scheme for major components in the ITER design, and the modes by which these components might fail. The identified failure modes are important first to safety, then to other areas, such as operational reliability. This preliminary list may need to be updated as more design details become available on the ITER design. The next step in this research is to provide failure rates for these component failure modes. These data will be entered into the Software Tool for the Analysis of Reliability and Safety (STARS) computer code for risk assessment. This work will support ITER safety work, such as for the Non Site-specific Safety Report (NSSR) and the Site Specific Safety Report (SSSR). This failure rate data assignation task will operate at a continuous but modest level of effort through January 1998. 


\section{MAGNET SAFETY}

Elliptic Integral Solution for Coaxial Current Filaments

J. S. Herring, ITER/US/95/TE/SA-28, September 19, 1995

This EDF contains the derivation of the radial and vertical magnetic fields from the vector potential due to a circular filamentary current loop. The solution makes use of the elliptic integral solution. The only approximation in the solution is that the coils are assumed to be filaments, i.e. the cross-section of the conductor is assumed to be zero. The derived solutions are:

$$
\begin{aligned}
& B_{\rho}(\rho, z)=\frac{\mu_{o} I}{2 \pi} a \sqrt{\left(1+\frac{\rho}{a}\right)^{2}+\left(\frac{z}{a}\right)^{2}} \frac{z}{\rho}\left[-K(k)+\frac{\left[1+\left(\frac{\rho}{a}\right)^{2}+\left(\frac{z}{a}\right)^{2}\right]}{\left[\left(1-\frac{\rho}{a}\right)^{2}+\left(\frac{z}{a}\right)^{2}\right]} E(k)\right] \\
& B_{z}(\rho, z)=\frac{\mu_{o} I}{2 \pi} \frac{1}{a \sqrt{\left(1+\frac{\rho}{a}\right)^{2}+\left(\frac{z}{a}\right)^{2}}}\left[K(k)+\frac{1-\left(\frac{\rho}{a}\right)^{2}-\left(\frac{z}{a}\right)^{2}}{\left(1-\frac{\rho}{a}\right)^{2}+\left(\frac{z}{a}\right)^{2}} E(k)\right]
\end{aligned}
$$

where $a$ is the radius of the coil, $z$ and $r$ are the vertical distance from the plane of the coil and the cylindrical radius to point in question, $I$ is the coil current and $\mathrm{K}$ and $\mathrm{E}$ are the complete elliptic integrals of the first and second kinds. Although the initial expression for the vector potential is in cgs units, all further derivation and the computational routines are in MKS (SI) units.

Appendices to the EDF contain:

1. The elliptic integral solution for the case where $\mathrm{k}$ is small, i.e. at locations along the $z$ axis, in the interior of the coil and far from the coil.

2. The dipole approximation for the fields far from the coil

3. The Hastings polynomial approximations for the elliptic integrals
4. The FORTRAN coding implementing the elliptic integral solution

5. Sample output from a spreadsheet using the elliptic integral/Hastings' approxi-mation method.

\section{Trajectory of a Ferromagnetic Object in} the Ex-Vessel Poloidal Field

J. S. Herring, ITER/US/95/TE/SA-30, October 2, 1995.

This EDF contains the development and initial applications of a program FERMAG which calculates the trajectory of a ferromagnetic object in the fringe poloidal fields surrounding ITER. During operation of ITER it is possible that small hand tools, bolts and other ferromagnetic objects may be inadvertently left in areas surrounding the cryostat. Where the poloidal field magnets are energized, the 
field gradients in the areas surrounding the reactor are sometimes sufficient of move those objects into areas of still stronger field gradients and finally to accelerate the unrestrained objects toward the reactor.

In ITER, the impact of an accelerated ferromagnetic object could damage vacuum windows, small manifolds, instrumentation and electrical connections. Ferromagnetic objects in the field gradient will also experience repeated lateral forces, whether or not they are free to be accelerated. Finally, injury to workers is possible if the area surrounding the magnets is occupied.

The EDF first derives the expressions for forces on ferromagnetic objects

$\mathbf{F}=\frac{\chi V B}{\mu_{o}} \mathrm{~S}|\mathbf{B}|$

and expressions for the change in direction and velocity as a result of inelastic impacts with used-specified barriers surrounding the reactor. Ferromagnetic saturation and gravity are included in determining the trajectory of the object.

The code is applied to typical small ferromagnetic objects left in the regions surround ITER. The code is not limited to small objects and it must be pointed out that objects as large as fork-lift tines have been drawn into MRI magnets. Appendices to the EDF contain:

1. A complete listing of the FERMAG code, including a listing of all variables and their units.

2. Input files and output files in the initial application of the code to the ITER exvessel fields.

3. A comparison of the results of the code with the forces on a ferromagnetic object as predicted by the dipole approximation.
4. A comparison of the fields and vector potential immediately surrounding the winding pack as determined in a singleturn with the same parameters calculated by a model where the coil contains 100 turns.

\section{Final Report on the Magnet Safety Design Task for 1994 and 1995 J. S. Herring, ITER/US/95/TE/SA-31, October 2, 1995.}

This EDF contains the summary and results of the magnet safety design task performed for the Naka Joint Work Site over 1994 and 1995. This task dwelled on risk assessment activities to support the Early Safety and Environmental Characterization Study and the Interim Design Report, and the task also dealt with some operational safety concerns for magnets, namely the acceleration of ferromagnetic objects left in the magnetic field.

Some of the findings from the risk work were that there is not a good data bank of component failure rates for magnets or their subcomponents. The Failure Modes and Effects Analyses showed interesting results that were highly similar to the designer's intuition of fault events of concern, but were arrived at in a documented, systematic way rather than using the brainstorming or intuition approaches. Methods to develop component failure rate data could be expert opinion, analyst judgment, manufacturer accelerated life testing, proof testing, or other means.

The ferromagnetic acceleration task resulted in a computer code that can calculate the trajectory, inelastic collision with barriers, and the velocity of ferromagnetic objects that might be left in the magnetic field (bolts, wrenches, etc.). The highest acceleration ob- 
jects found in the test cases performed were those accelerated from the floor beneath the cryostat. This issue will require more in depth analysis in the future. 


\section{FUSION SAFETY COMPUTER CODE DEVELOPMENT}

Investigation of the Two-Dimensional

Effect on the One-Dimensional Conduction Model for the ITER Outline Blanket Design

M. J. Gaeta, G. L. Hawkes, ITER/US/95/TE/SA-01, January 27, 1995

The purpose of this work was to investigate the accuracy of the 1-D CHEMCON models that include parallel conduction and radiation heat transfer in highly voided regions of the ITER blanket. To determine the accuracy of the CHEMCON model, a comparison was made between a two-dimensional finite element model of a portion of the ITER blanket and an equivalent 1-D CHEMCON model of the same geometry. An attempt was made to develop a correction to the 1-D CHEMCON model to allow the mean temperatures predicted by this model to more closely match the 2-D finite element model mean temperatures. A concern in applying the CHEMCON modeling scheme is that the effective conductance may be overestimated because of the additional conduction length that the energy must traverse to circumvent the coolant channel. It is also clear that the conduction path could be decreased if conducting ribs were added to the channel.

The following methodology was used to determine the needed correction factor for the conduction length within the highly voided region models used in the 1-D CHEMCON code. A 2-D finite element model was constructed for each of the cases. Then, the conduction lengths used by the conduction heat transfer module within the CHEMCON code were varied until the mean temperatures reported by CHEMCON matched at the selected points to $1 \%$.
The conduction length multiplier derived in this work ranged from 1.75 to 2.3 for a $95 \%$ voided region for the $0.32 \mathrm{-m}$ channel blanket model. For the $0.5-\mathrm{m}$ channel blanket model, the required multiplier ranged from 3.1 (no strut) to 2.1 (one strut). The results showed that in the absence of a conduction length multiplier, for the idealized cases considered, the temperature was underpredicted by CHEMCON by up to $16 \%$ for the $0.32-\mathrm{m}$ channel model and by $22 \%$ for the $0.5-\mathrm{m}$ channel model. This underprediction is significant in that the behavior of the hydrogen production rates is exponentially dependent on the beryllium first wall temperatures during the transient, and this underprediction in temperature will likely result in an underprediction of the amount of hydrogen generated. In addition, the results showed that for blanket designs with long, evacuated channels, the conduction length multiplier used for the 1-D CHEMCON model varies nearly linearly with the channel halflength. The transient results showed that with the appropriate conduction length multipliers, transient temperatures predicted by the 1-D CHEMCON code can roughly approximate those predicted by the 2-D finite element model.

It is recommended that future CHEMCON 1-D models incorporate the conduction length multiplier derived in this work for highly voided regions in the ITER blanket. In addition, the dramatic decrease in the mean and peak temperatures at the front of the blanket achieved through the use of small conduction ribs is a compelling argument for the redesign of the blanket coolant channels to increase the effective radial conductivity through the blanket of the ITER outline design. 
MELCOR Ex-Vessel LOCA Analyses in Support of ESECS

B. J. Merrill, ITER/US/95/TE/SA-03, February 27, 1995.

The purpose of this Engineering Design File (EDF) is to report on work that was performed to support the Early Safety and Environmental Characterization Study (ESECS). In particular, this work determines the time for first wall and divertor melt, an estimate of the amount of hydrogen generated within the vacuum vessel, the fraction of this hydrogen released from the stack, and an estimate of the pressurization of the equipment vaults during ex-vessel (outside of the vacuum vessel) loss-of-cooing accidents (LOCAs). Four LOCA scenarios caused by guillotine pipe ruptures inside of the equipment vaults were examined for the first wall/shield blanket (FW/SB) and divertor cooling systems. Ruptures of $0.8-\mathrm{m}$ and $0.16-$ $\mathrm{m}$ pipes were considered for the FW/SB cooling system. Ruptures of $0.3-\mathrm{m}$ and $0.13-$ $\mathrm{m}$ pipes were considered for the divertor cooling system. For each of these scenarios, plasma burn was assumed to continue until the failure of the first wall or divertor by melting induces a plasma disruption by injecting cooling water into the plasma chamber. These failures allow for a possible pathway to release the tritium retained by the plasmafacing components within the vacuum vessel. In the following five sections we describe the configuration of ITER FW/SB and divertor cooling systems, present the models we developed for the MELCOR code to simulate these cooling systems, describe the results obtained, and summarize our findings.

A guillotine break of a hot vault pipe (i.e., a large break) in the FW/SB cooling system results in de-pressurization from $2.15 \mathrm{MPa}$ to
$0.25 \mathrm{MPa}$ and dryout of the FW coolant within $50 \mathrm{~s}$ of the break. Pressures in the vault rapidly reached the vault design pressure of $0.17 \mathrm{MPa}$ as a result of $8.2 \times 10^{4} \mathrm{~kg}$ of water entering the vault through the break, and venting of the vault to the stack occurred. The FW surface temperature rose linearly for $103 \mathrm{~s}$ until the FW copper completely melted through. Subsequent to $\mathrm{FW}$ failure, $500 \mathrm{~kg}$ of water was injected into the vacuum vessel. This water reacted with the hot beryllium of the FW to generate $102 \mathrm{~kg}$ over the first day of this accident. This quantity of hydrogen resulted in a deflagration 20 hours into the accident, causing a $0.4-\mathrm{MPa}$ pressure spike that resulted in a small puff of hydrogen gas exiting the stack. The quantity of hydrogen released was about $16 \mathrm{~g}$, which translates into a hydrogen release fraction of $1.6 \times 10^{-4}$.

A guillotine break of a cooling loop pipe (i.e., a small break) caused the FW coolant pressure to drop from $2.1 \mathrm{MPa}$ to $1.1 \mathrm{MPa}$ in $50 \mathrm{~s}$. After this time FW/SB loop pressures rose, due to loop heatup from plasma heating, until FW failure occurred $185 \mathrm{~s}$ after the start of the LOCA. Approximately $8,000 \mathrm{~kg}$ of water entered the vacuum vessel during this accident. However, only $8.6 \mathrm{~kg}$ of hydrogen is generated due to the added convective cooling associated with the larger water release into the vacuum chamber of the small break LOCA. The vault pressure also exceeds the vault design pressure of $0.17 \mathrm{M}$ After this time FW/SB loop pressures rose, due to loop heatup from plasma heating, until FW failure occurred $185 \mathrm{~s}$ after the start of the LOCA. Approximately $8,000 \mathrm{~kg}$ of water entered the vacuum vessel during this accident. However, only $8.6 \mathrm{~kg}$ of hydrogen is generated due to the added convective cooling associated with the larger water release into the vacuum chamber of the small break LOCA. The vault pressure 
of the small break LOCA. The vault pressure also exceeds the vault design pressure of 0.17 $\mathrm{MPa}$, and venting occurs through the stack. Of the $8.6 \mathrm{~kg}$ of hydrogen generated, only about $5.5 \mathrm{~g}$ are released, which translates into a hydrogen release fraction of $6.4 \times 10^{-4}$ for the small-break LOCA.

The results for the large and small break of the divertor coolant loop appear to be less severe in that there was no hydrogen released through the stack. The smaller liquid inventory in the divertor coolant system (22 $\mathrm{m}^{3}$ ) compared to the FW/SB coolant loop inventory $\left(120 \mathrm{~m}^{3}\right)$ leads to lower pressures within the vault after the break. Hence, the rupture disk between the vault and the filter stack, which is designed to break at $0.7 \mathrm{MPa}$ never ruptures in the divertor ex-vessel LOCA cases. Although the divertor surface temperature reaches $1,900 \mathrm{~K}$ before melting of the divertor, there is no available water for the Be-steam reaction. After the failure of the divertor, there is available water for the $\mathrm{Be}$ steam reaction, but the divertor surface is rapidly quenched by the coolant blowdown into the plasma chamber. Hence, less than 0.1 $\mathrm{g}$ of hydrogen is produced.

\section{Research and Development Plan for System-Level Transient Thermal- Chemical Codes}

B. J. Merrill, ITER/US/95/TE/SA-9, May 2, 1995.

This ITER U.S. Home Team Safety Engineering Design File (EDF) contains a research and development plan for ITER task $S$ 81 TT 95-02-28 FU, subtask 2, entitled: System-Level Transient Thermal-Chemical Codes. This plan covers a three and one-half year period, and was developed from guidance sup- plied by the ITER JCT Safety Group. The objectives of this task are to select, modify, develop, and validate and verify (V\&V) computer codes for use in future ITER safety analyses. This work is a continuation of that performed in 1994 under tasks NID-7a,b. The thermal-chemical system codes under development by this task will have the capability of predicting coolant pressure, temperature, and mass flow rate in ITER's cooling and cryogenic systems, and in the confinement systems during loss-of-coolant accidents (LOCAs), as well as structural temperatures (i.e., first wall, blanket, divertor, and vacuum vessel) and transport of aerosols produced by oxidation of structural surfaces.

The computer codes under development are: ATHENA, CHEMCON, and MELCOR. ATHENA is a one-dimensional thermal hydraulics code that can be used for detailed modeling of fusion reactor cooling systems that contain either water, liquid metals, or cryogens as coolants. CHEMCON is a one-dimensional heat conduction code that can be used as a scoping tool for determining fusion reactor temperatures and hydrogen production from plasma-facing components (PFCs) reacting with water during long-term in-vessel LOCAs. MELCOR is a thermal hydraulics/aerosol transport code that can be used to determine confinement system pressurization and activated material transport during hypothetical accidents (i.e., unmitigated LOCAs).

The proposed research and development plan for this subtasks will make these codes more ITER relevant. The proposed cost for this plan is approximately 1250 IUAs over three and one-half years. Twenty-five milestones have been proposed as a measure of progress towards the proposed task objectives. The proposed work in this 
subtask is based on assumed levels of U.S. funding. This plan will be revisited and discussed with the JCT if funding levels change or the JCT determines that research and development priorities have changed in this area.

\section{Additional MELCOR EX-Vessel LOCA Analyses in Support of ESECS \\ M. J. Gaeta, B. J. Merrill, ITER/US/95/TE/SA-14, May 30, 1995.}

Five LOCA scenarios caused by a guillotine break of the hot plenum within the HTS vault were studied. These include LOCAs for both the Garching November and March FW/SB designs. For the November design, a two-loop cooling configuration was studied. A LOCA in the FW cooling system while the blanket cooling system remains operable, and a LOCA in the blanket cooling system while the FW cooling system remains operable were examined. For the March design, both a one-loop and a two-loop cooling configuration were studied. For the two-loop cooling configuration, a LOCA in the FW cooling system while the shield cooling system remains operable, and a LOCA in the shield cooling system while the FW cooling system remains operable were examined. For the one loop configuration, the LOCA causes a complete cooling loss to the FW/SB.

For each of these scenarios, plasma burn was assumed to continue until the failure of the FW or SB occurred by melting and induced a plasma disruption by injecting cooling water into the plasma chamber. These failures allow for a possible pathway to release the tritium retained by the plasma-facing components within the vacuum vessel, and allow for the possibility of hydrogen generation by FW be- ryllium/water chemical reactions. MELCOR models for both the November and March FW/SB designs and associated cooling systems were developed.

A FW cooling system LOCA for the November FW/SB design does not result in FW melting. The FW temperature excursion is limited by conduction of the FW heating into the shield, which is cooled by a separate cooling system. However, if it were assumed that FW failure occurs at the predicted maximum temperature (below the FW melting point) only 20 grams of hydrogen would be produced. A SB cooling system large LOCA for the November design results in melting of the SB. There is negligible hydrogen produced following SB failure because the FW temperature never exceeds its normal operating value. However, the failure of the SB raises safety issues regarding an open pathway for material transport produced from molten stainless steel-water oxidation reactions.

A LOCA in the single-loop cooling system configuration of the March FW/SB design results in FW failure by copper melting within 235 seconds of LOCA initiation. The amount of hydrogen generated in the VV after FW failure was $73 \mathrm{~kg}$. The beryllium-steam reaction did not achieve auto-ignited conditions following plasma burn termination, even though the FW achieved a temperature of about $1,400 \mathrm{~K}$. However, the same could not be said for a FW LOCA in a two-loop cooling system configuration for the March FW/SB design, where the FW temperature rose to about $1,500 \mathrm{~K}$ before decaying, resulting in $180 \mathrm{~kg}$ of hydrogen being produced. This autoignition condition for the FW beryllium was avoided by the consumption of available steam in the VV. The time to $\mathrm{FW}$ failure for this LOCA was 365 seconds. A LOCA in the 
shield cooling system of the two-loop cooling configuration of the March FW/SB design is a benign accident, producing a maximum shield temperature of only $720 \mathrm{~K}$.

\section{Initial Modifications to the MELCOR Code \\ B. J. Merrill, ITER/US/95/TE/SA-18, June 30, 1995.}

This ITER Engineering Design File (EDF) describes those modifications made to the MELCOR code prior to June of 1995 under ITER Joint Central Team Task Agreement S 81 TT 03 95-02028 FU, subtask 2, entitled: System Level Transient Thermal-Chemical Codes. The purpose of this task is to develop thermal-chemical computer codes for use in ITER safety analyses. These codes will be needed to assess the thermal hydraulic response of cooling systems in ITER during loss of cooling accidents (LOCAs) for the ITER Engineering Design Activity (EDA), and must have the capability to predicting coolant pressure, temperature, and mass flow rate in ITER cooling, cryogenic, and confinement systems. These codes must also predict structural temperatures (i.e., first wall, blanket, divertor, and vacuum vessel) resulting from energy produced by radioactive decay heat or chemical reactions, and the transport of aerosols produced by oxidation of these structures.

The MELCOR code is one of the codes being modified under this task. Initial thermal hydraulic modifications have been made to MELCOR that address water freezing, air condensation, and beryllium carbon and tungsten oxidation in steam environments. This EDF contains the equations associated with these modifications, test problems developed to assess the execution of the modified MELCOR code, and the results obtained for these test problems. The adopted test problems described in this EDF are not indicative of accident scenarios for ITER, or of the safety performance of ITER. A listing of the FORTRAN coding changes made to certain MELCOR subroutines is contained in the appendices of this EDF.

\section{MELCOR ITER LOCA Sensitivity Calculations in Support of ESECS M. J. Gaeta, ITER/US/95/TE/SA-20, August 11, 1995.}

The purpose of this Engineering Design File (EDF) is to describe work that was performed to support the Early Safety and Environmental Characterization Study (ESECS). This work extends previous work that examined ex-vessel loss-of-cooling-accidents (LOCAs) modeled in single and two-loop cooling configurations. The previous work describes MELCOR models of the Garching November FW/SB and the March FW/SB design. In this work, a series of modifications to the single loop March FW/SB design were performed to make the single loop March FW/SB model more consistent with ITER Interim FW/SB design. Studies were performed at different stages of model evolution. Most of these studies include the assumption of an ex-vessel LOCA occurring in the FW/SB cooling system. In all studies, plasma disruption is assumed coincident with an in-vessel breach in the coolant system.

In the first study, the hydrogen production sensitivity to structural integration of the FW and SB components was examined. It was found that the hydrogen produced was decreased by $11 \%$ from $73 \mathrm{~kg}$ to $65 \mathrm{~kg}$. The second study consisted of a series of sensitivity calculations that were performed by varying 
the FW temperature-induced plasma disruption point. It was found that assuming a FW temperature-induced plasma disruption point of about $1100 \mathrm{~K}$ resulted in about $5 \mathrm{~kg}$ of hydrogen and that the amount of hydrogen produced depended nearly exponentially on the FW temperature.

The third study consisted of the addition of a volume representing a coolant system not affected by the ex-vessel LOCA. This additional loop was allowed to undergo an invessel LOCA and without simultaneous failure of the loop undergo the ex-vessel LOCA. This was done to examine scenarios in which the partial steam pressure is maximized to determine this effect on the total amount of hydrogen produced. Using the $1000-\mathrm{K} \mathrm{FW}$ temperature-induced plasma disruption case described in the second study, it was found that assuming simultaneous failure of the loop undergoing the ex-vessel LOCA resulted in 7.7 $\mathrm{kg}$. If only the second loop underwent an invessel LOCA, about $10.6 \mathrm{~kg}$ of hydrogen was produced. In both cases, the increase in steam pressure played a key role in increasing the hydrogen produced.

The fourth study consisted of an updated single loop model that was consistent with the IDR design. The inventories and flow areas of this model were increased to produce two models, each with a single coolant loop that approximated 2 and 4 Type-I cooling loops, respectively. The single loop in each case then underwent an in-vessel LOCA in order to estimate the maximum vapor generation rate and mass flows through the vacuum ducts to the suppression pool. Estimates of these quantities are needed to aid suppression system design. The maximum vapor generation rates were 5,700 and $7,300 \mathrm{~kg} / \mathrm{s}$ for the two- and four-loop cases, respectively. The maximum mass flow rates at the first wall were 30,000 and $37,000 \mathrm{~kg} / \mathrm{s}$ and 2,000 and $3,000 \mathrm{~kg} / \mathrm{s}$ at the vacuum duct connections for the two and four loop cases, respectively.

The fifth and last study involved sensitivity calculations on the size of the exvessel break for the November divertor design. This was done to determine the effect on the time to in-vessel divertor surface breach (defined by the copper melting temperature) and the amount of hydrogen produced. These sensitivity studies indicate that break sizes ranging from $0.14 \mathrm{~m}^{2}$ to $1 \mathrm{~cm}^{2}$ do not result in excessive hydrogen production with all amounts below $0.3 \mathrm{~kg}$.

\section{MELCOR Reference Problem Calculations for JCT Benchmarking Exercise \\ E. J. Gracyalny, ITER/US/95/TE/SA-23, September 11, 1995.}

The purpose of this Engineering Design File (EDF) is to document the results of a series of reference problems performed using Version 1.8.2 of MELCOR with additional modifications added by the INEL.. The first case consisted of a model of a coolant blowdown into a low-pressure volume. Successive models build upon this first model and increase in complexity. Case 2 adds vertical and horizontal solid structures which represent the wall and floor of the vacuum vessel, respectively, Cases 3 and 4 add a vertical then a horizontal beryllium/copper solid structure representing a first wall and divertor component, respectively. Case 5 adds a stainless steel solid structure to the back of the first wall and divertor structure, respectively, and models any hydrogen produced during beryllium-steam reactions. Finally, Case 6 adds a suppression tank volume 
nally, Case 6 adds a suppression tank volume to the model.

Variations were considered for Cases 3 and 5 designated sub-cases $a$ and $b$. Case $3 a$ was the original Case 3 , while case $3 b$ added a divertor solid structure without a stainless steel backing. Case 5a was the original Case 5, while Case $5 \mathrm{~b}$ used elevated FW temperatures to examine the effect on the hydrogen produced. Finally, starting with Case $3 a$, we performed parallel calculations using the pseudoaxial conduction (PAC) model for the vertical FW heat structure. The PAC model was developed to simulate axial conduction in a submerged one-dimensional heat structure.

Most VV pressures peak between 1 and 1.5 MPa. Model 6 incorporates the suppression tank giving rise to the increased blowdown volume and thus $\mathrm{VV}$ pressures do not exceed $0.7 \mathrm{MPa}$. The vacuum vessel wall temperatures peak near $470 \mathrm{~K}$ and trend downward to about $410 \mathrm{~K}$ at the end of the one-hour transient. This downward trend is due to the cooling on the outside of the vessel. The vertical wall temperature is higher than the floor temperature because the incoming water forms a cooling pool on the bottom horizontal VV heat structure, but it is only partially in contact with the vertical wall $\mathrm{WV}$ heat structure.

The temperature of the left-hand side of the vertical first wall is much lower for Cases 4 and higher than for $3 a$ and $3 b$. This is due to the addition of the thick stainless steel slab at a lower temperature in the later models. A rapid decrease of $\mathrm{FW}$ temperature occurs at about 100 seconds due to the water quenching the bottom of the heat structure. Compare this with the temperatures for the horizontal divertor structure which drop immediately because it is entirely immersed in water very quickly. Hydrogen produced for all cases starting with Case $5 \mathrm{a}$, is less than $1 \mathrm{mg}$. In Case $5 b$, when the temperature of the beryllium is increased to $1000 \mathrm{~K}$, much more hydrogen is generated, but is still quite insignificant relative to ITER flammability limits.

The effect of the suppression tank is to greatly decrease the pressure and temperatures of the system. The pressure in the suppression tank closely follows that of the vacuum vessel after rupture disk failure. After the initial spike, the suppression tank pressure trails off due to the constant cooling of the vacuum vessel. The temperatures in the suppression tank increase slightly and then stay fairly constant throughout the problem. The flow between the two volumes occurs entirely in the first 200 seconds when the two volumes are equilibrating.

\section{Addition of Helium Properties to the MELCOR Code}

D. L. Hagrman, ITER/95/US/TE/SA-24, September 29, 1995.

This ITER Engineering Design File (EDF) describes modifications made to the MELCOR computer code to incorporate an Equation of State (EOS) for helium. The capability to model the behavior of helium is required for safety analysis of ITER cryogenic systems.

The modifications include the addition of an EOS for pressure as a function of temperature and density (or specific volume) for temperatures from $2,177 \mathrm{~K}$ to $1500 \mathrm{~K}$ and densities from the liquidus line (where freezing begins at pressures above 25 atmospheres). This EOS is the result of a definitive fit to 
extensive data by Robert D. McCarty of the United States Bureau of Standards. Consistent expressions for the entropy, enthalpy, pressure derivatives with respect to temperature and density, and the specific heat capacity are also provided.

This EDF contains the equations needed to describe the helium properties mentioned in the preceding paragraph, a discussion of the method used to implement the equations in MELCOR, comparisons to selected values of helium properties published by McCarty, test problems developed to assess the execution of the modified MELCOR code, and results obtained for these test problems. The adopted test problems described in this EDF are not indicative of accident scenarios for ITER, or of the safety performance of ITER. Listings of the FORTRAN coding used in conjunction with revisions of the affected MELCOR subroutines are contained in Appendix B of this EDF. 